\title{
Potential role of new anticoagulants for prevention and treatment of venous thromboembolism in cancer patients
}

This article was published in the following Dove Press journal:

Vascular Health and Risk Management

7 May 2013

Number of times this article has been viewed

\author{
Antonio Gómez-Outes \\ M Luisa Suárez-Gea' \\ Ramón Lecumberri² \\ Ana Isabel Terleira- \\ Fernández ${ }^{3,4}$ \\ Emilio Vargas-Castrillón ${ }^{3,4}$ \\ Eduardo Rocha ${ }^{5}$ \\ 'Division of Pharmacology and \\ Clinical Evaluation, Medicines for \\ Human Use, Spanish Agency for \\ Medicines and Medical Devices, \\ Madrid, ${ }^{2}$ Department of Hematology, \\ University Clinic of Navarra, \\ Pamplona, ${ }^{3}$ Department of Clinical \\ Pharmacology, Hospital Clínico, \\ Madrid, ${ }^{4}$ Department of Pharmacology, \\ Universidad Complutense, Madrid, \\ ${ }^{5}$ Department of Hematology, School \\ of Medicine, University of Navarra, \\ Pamplona, Spain
}

\begin{abstract}
Venous thromboembolism (VTE), encompassing deep vein thrombosis and pulmonary embolism, represents a major cause of morbidity and mortality in patients with cancer. Low molecular weight heparins are the preferred option for anticoagulation in cancer patients according to current clinical practice guidelines. Fondaparinux may also have a place in prevention of VTE in hospitalized cancer patients with additional risk factors and for initial treatment of VTE. Although low molecular weight heparins and fondaparinux are effective and safe, they require daily subcutaneous administration, which may be problematic for many patients, particularly if long-term treatment is needed. Studying anticoagulant therapy in oncology patients is challenging because this patient group has an increased risk of VTE and bleeding during anticoagulant therapy compared with the population without cancer. Risk factors for increased VTE and bleeding risk in these patients include concomitant treatments (surgery, chemotherapy, placement of central venous catheters, radiotherapy, hormonal therapy, angiogenesis inhibitors, antiplatelet drugs), supportive therapies (ie, steroids, blood transfusion, white blood cell growth factors, and erythropoiesis-stimulating agents), and tumor-related factors (local vessel damage and invasion, abnormalities in platelet function, and number). New anticoagulants in development for prophylaxis and treatment of VTE include parenteral compounds for once-daily administration (ie, semuloparin) or once-weekly dosing (ie, idraparinux and idrabiotaparinux), as well as orally active compounds (ie, dabigatran, rivaroxaban, apixaban, edoxaban, betrixaban). In the present review, we discuss the pharmacology of the new anticoagulants, the results of clinical trials testing these new compounds in VTE, with special emphasis on studies that included cancer patients, and their potential advantages and drawbacks compared with existing therapies.
\end{abstract}

Keywords: anticoagulants, venous thromboembolism, cancer, dabigatran, apixaban, rivaroxaban

\section{Introduction}

Venous thromboembolism (VTE), encompassing deep vein thrombosis and pulmonary embolism, is the third leading cause of mortality due to circulatory diseases, second only to myocardial infarction and stroke. ${ }^{1}$ On the other hand, cancer is responsible for $25 \%$ of all deaths in developed countries, ${ }^{2}$ only exceeded by circulatory diseases. The two-way association between thrombosis and cancer has been well established since the first description by Jean Baptiste Bouillaud in $1823,{ }^{3}$ developed further by Armand Trousseau in $1865 .{ }^{4}$ Patients with cancer have at least a six-fold increased risk of VTE compared with those without cancer, ${ }^{5}$ and the diagnosis of VTE in cancer patients is associated with a $2-4$-fold decreased survival during the first year.
Correspondence: Antonio Gómez-Outes Division of Pharmacology and Clinical Evaluation, Medicines for Human Use, Spanish Agency for Medicines and Medical Devices, Parque Empresarial

"Las Mercedes", Edificio 8,

C/Campezo I, Madrid 28022, Spain

$\mathrm{Tel}+349|822575|$

Fax +34918225161

Email agomezo@aemps.es 
Conversely, VTE can be the first sign of a cancer. Patients in the general population who develop symptomatic VTE have a 2-4-fold increased risk of cancer diagnosis in the first year after the VTE event. ${ }^{7,8}$

Studying anticoagulant therapy in oncology patients is challenging for several reasons. First, there are differences in VTE risk across the cancer population. Certain cancers (metastatic cancer, pancreas, ovary, lung, colon, stomach, prostate, and kidney adenocarcinomas, as well as malignant brain tumors and hematological malignancies) are strongly associated with the development of VTE. ${ }^{9}$ Therapies for cancer, such as surgery, chemotherapy, and placement of central venous catheters, radiotherapy, hormonal manipulation (eg, tamoxifen), angiogenesis inhibitors (eg, bevacizumab, thalidomide, lenalidomide), and supportive therapies (ie, steroids, blood transfusion, white blood cell growth factors, and erythropoiesis-stimulating agents) may also increase the risk of VTE. ${ }^{10,11}$ Further, cancer patients have an increased risk of excessive bleeding during anticoagulant therapy compared with the population without cancer, ${ }^{12}$ which may have several causes, including surgery, liver failure, chemotherapy, radiotherapy, use of antiplatelet drugs, or tumor-related factors (local vessel damage and invasion, abnormalities in platelet functioning and number). ${ }^{10}$

Low molecular weight heparins (LMWH) are preferred over other anticoagulants (ie, fondaparinux, unfractionated heparin) or vitamin K antagonists (ie, warfarin, acenocoumarol) in cancer patients, according to clinical practice guidelines published by the American College of Chest Physicians, ${ }^{13-15}$ the GFTC initiative, ${ }^{16}$ the European Society of Medical Oncology, ${ }^{17}$ the American Society of Clinical Oncology, ${ }^{18}$ and the National Comprehensive Cancer Network. ${ }^{19}$ Fondaparinux may be an alternative to LMWH for prevention of VTE in hospitalized cancer patients with at least one additional risk factor for VTE, and for initial treatment of VTE, but it is not generally recommended for prevention of VTE after cancer surgery or for long-term or extended treatment of VTE (Table 1). ${ }^{13-15}$ Unfractionated heparin may provide an alternative to LMWH and fondaparinux in patients with renal impairment. ${ }^{15}$ The preference for LMWH over vitamin $\mathrm{K}$ antagonists in cancer patients is based on several considerations: LMWH is more effective than vitamin $\mathrm{K}$ antagonists and is equally safe in the long-term treatment of VTE; ${ }^{15} \mathrm{LMWH}$ is easier to handle than vitamin $\mathrm{K}$ antagonists in the event of invasive procedures, which are frequent in cancer patients and may require rapid reversal with rapid reintroduction of anticoagulation; there may be an unpredictable response to vitamin $\mathrm{K}$ antagonist therapy in cancer patients because of the high risk of drug-drug interactions with cancer chemotherapy, as well as the frequent presence of vomiting associated with chemotherapy and subsequent poor oral absorption; ${ }^{15}$ vitamin $\mathrm{K}$ antagonists have a slow onset of action, which implies a need for overlap with a parenteral anticoagulant in the event of acute VTE; and the narrow therapeutic window and variability in response to vitamin $\mathrm{K}$ antagonists implies that frequent anticoagulant monitoring [using the prothrombin time and its reporting as the international normalized ratio (INR)] is necessary to avoid subtherapeutic anticoagulation associated with an increased risk of thrombosis or excessive anticoagulation that increases the risk of bleeding. Such monitoring is inconvenient for patients and medical staff, and costly for health care payers.

Despite LMWH and fondaparinux being effective and safe, they still require daily parenteral subcutaneous administration, which may be problematic for many patients, particularly if long-term treatment is needed. In addition, they are cleared mainly through the kidneys, and their use in patients with severe renal insufficiency may be problematic. LMWH is only partially neutralized by protamine, and no specific antidote is available for fondaparinux.

New anticoagulants include parenteral compounds for once-daily administration (ie, semuloparin) or once-weekly dosing (ie, idrabiotaparinux), as well as orally active compounds (ie, dabigatran, rivaroxaban, apixaban, edoxaban, betrixaban).

In this review, we discuss the pharmacology of the new anticoagulants and the results of clinical trials testing these compounds in VTE, with special emphasis on studies that included cancer patients. With this objective, we searched Medline (up to December 1, 2012) and clinical trial registries (ie, clinicaltrials.gov) using the terms "cancer", "semuloparin", "idraparinux", "idrabiotaparinux", "rivaroxaban", “apixaban", "edoxaban", "betrixaban”, and "dabigatran". We also searched regulatory agency websites (US Food and Drug Administration, European Medicines Agency) and relevant conference proceedings related to anticoagulation and cancer, ie, International Conference of Thrombosis and Hemostasis Issues in Cancer, International Society of Thrombosis and Hemostasis, American Society of Clinical Oncology, American Society of Hematology, and Mediterranean League Against Thromboembolic Diseases.

\section{Mechanism of action of new anticoagulants}

The new anticoagulants that are currently approved or in clinical development for indications related to the 





prophylaxis and treatment of VTE target activated Factor X (FXa) or activated factor II (FIIa, thrombin, Figure 1).

FXa controls generation of thrombin, and inhibition of one molecule of FXa may result in inhibition of generation of 1000 molecules of FIIa. ${ }^{20}$ Thrombin plays a central role in hemostasis by regulating blood coagulation and inducing platelet aggregation. ${ }^{21}$ It is formed from its precursor, prothrombin, and converts fibrinogen to fibrin in the final step of the clotting cascade (Figure 1). Thrombin also promotes numerous cellular effects, ie, it plays a role in inflammation and cellular proliferation, and displays mitogen activity in smooth muscle cells and endothelial cells, predominantly by activation of angiogenesis. ${ }^{22}$ Preclinical data suggest that thrombin inhibition may result in inhibition of both tumor growth and metastases. ${ }^{23,24}$ Therefore, use of anticoagulation in cancer patients might be beneficial not only in preventing thrombotic events, but also as an adjuvant anticancer therapy.

FXa inhibitors block generation of thrombin, while thrombin inhibitors block the activity of thrombin. FXa inhibitors include parenteral drugs that indirectly inhibit FXa by binding to antithrombin (ie, semuloparin, idraparinux, idrabiotaparinux) and orally active agents that directly inhibit FXa (rivaroxaban, apixaban, edoxaban, betrixaban). Oral direct thrombin inhibitors include the prodrug dabigatran etexilate, AZD0837, and S35972. ${ }^{25}$

Development of several promising new oral direct FXa inhibitors for VTE has recently been halted, including for darexaban (YM150, Astellas Pharma Inc, Tokyo, Japan), ${ }^{26}$ letaxaban (TAK-442, Takeda Pharmaceutical Company

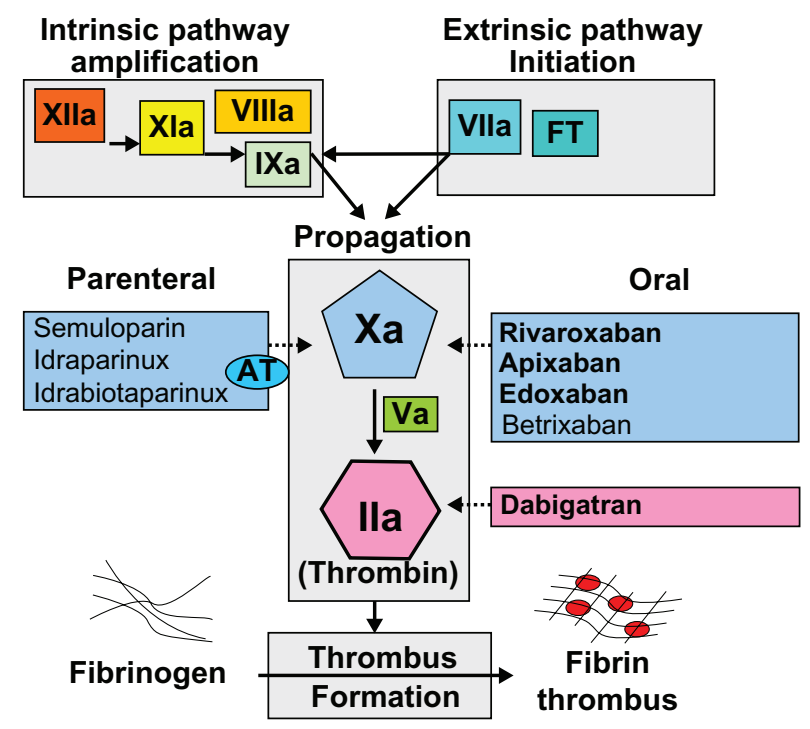

Figure I New anticoagulants and their targets in the coagulation cascade.* Note: *Continuous line indicates activation; dashed line indicates inhibition.
Limited, Tokyo, Japan), eribaxaban (PD0348292, Pfizer Inc, New York, NY, USA), ${ }^{27}$ AZD0837, and S35972. These new anticoagulants will not be discussed further in the review.

Among the new anticoagulants, dabigatran etexilate (Pradaxa $^{\circledR}$, Boehringer Ingelheim, Ingelheim, Germany), rivaroxaban (Xarelto ${ }^{\circledR}$, Bayer HealthCare, Leverkusen, Germany), and apixaban (Eliquis ${ }^{\circledR}$, Bristol-Myers Squibb, New York, NY, USA) are currently approved in the European Union, the US, and other regions in several indications related to anticoagulation, while edoxaban (Lixiana ${ }^{\circledR}$, Daiichi-Sankyo Inc, Parsippany, NJ, USA) is approved in Japan for thromboprophylaxis after major orthopedic surgery (Table 2).

\section{Novel parenteral indirect FXa inhibitors \\ Semuloparin}

Semuloparin sodium (AVE5026, Mulsevo ${ }^{\circledR}$, Sanofi-Aventis, Bridgewater, NJ, USA) is a new ultralow molecular weight heparin obtained by phosphazene-promoted depolymerization of heparin from porcine intestinal mucosa, leading to a pool of polysaccharide chains with an individual molecular weight distribution (mean molecular weight 2000-3000 Da). ${ }^{28-30} \mathrm{It}$ has predominantly anti-FXa activity (ratio anti-FXa/anti-FIIa approximately 80) and a half-life of 16-20 hours, which allows once-daily subcutaneous administration. Its excretion is mainly renal. ${ }^{28}$ At equipotent doses, semuloparin did not affect bleeding parameters, whereas enoxaparin showed increased risk of hemorrhage in rats, rabbits, and dogs. ${ }^{29}$ The anticoagulant effects of semuloparin are not neutralized by protamine. ${ }^{31}$ Preliminary in vitro evaluation of semuloparin indicates a low risk for immune-mediated heparin-induced thrombocytopenia. ${ }^{29}$

Semuloparin was at least as effective as enoxaparin in preventing VTE after total knee arthroplasty (SAVEKNEE study) ${ }^{32}$ and total hip replacement (SAVE-HIP1 and SAVE-HIP2 studies), ${ }^{32}$ and was more effective than placebo for extended VTE prophylaxis after hip fracture surgery. ${ }^{33}$ However, no superior efficacy to enoxaparin was shown for major VTE (after excluding asymptomatic distal deep vein thrombosis) in a pooled analysis, ${ }^{34}$ and the risk of clinically relevant bleeding with semuloparin varied across trials.

Two additional studies were conducted in cancer patients undergoing chemotherapy (SAVE-ONCO) $)^{35-37}$ and in patients undergoing major abdominal surgery, the majority of them because of cancer (SAVE-ABDO). ${ }^{36-38}$ 
The results of these studies are shown in Table 3 and discussed below.

\section{VTE prophylaxis in medical patients undergoing chemotherapy}

SAVE-ONCO ${ }^{35-37}$ was a double-blind multicenter trial evaluating the efficacy and safety of semuloparin for prevention of VTE in patients receiving chemotherapy for cancer. A total of 1150 patients with metastatic or locally advanced solid tumors and embarking on a course of chemotherapy were randomly assigned to receive subcutaneous semuloparin $20 \mathrm{mg}$ once daily or placebo for a median of 3.5 months. The most common primary malignancies were lung (37\%) or colorectal $(29 \%)$ cancer, with a smaller proportion of patients having cancer of the stomach $(13 \%)$, ovary $(12 \%)$, pancreas $(8 \%)$, or bladder $(2 \%)$. Most patients $(69 \%)$ had metastatic disease at study entry, and more than $90 \%$ of patients in this trial had Eastern Cooperative Oncology Group performance status of 0 or $1 .^{36,37}$ The most common chemotherapeutic agents included platinum compounds and pyrimidine analogs. In total, $42 \%$ of patients had at least one additional VTE risk factor, and $2.3 \%$ of patients had at least three VTE risk factors.

The primary efficacy outcome (composite of any symptomatic deep vein thrombosis, any nonfatal pulmonary embolism, and death related to VTE) occurred in 1.2\% of patients (20/1608) receiving semuloparin, as compared with 3.4\% (55/1604) receiving placebo (absolute risk difference $-2.2 \%$; hazard ratio [HR] $0.36 ; 95 \%$ confidence interval [CI] 0.21-0.60; $P<0.001)$. VTE-related death occurred in only $0.4 \%$ and $0.6 \%$ of patients receiving semuloparin and placebo, respectively. In relative terms, efficacy was consistent among subgroups defined according to the origin and stage of cancer and the baseline risk of VTE. However, the subgroup analyses also suggest that there may be a sizable variation in the absolute benefit depending on tumor type and baseline VTE risk between patients, with pancreatic subtype and a VTE risk score $\geq 3$ being associated with greater absolute benefit (absolute risk reduction 8.5\% and $3.9 \%$ versus placebo, respectively). ${ }^{36,37}$

The incidence of clinically relevant bleeding was $2.8 \%$ and $2.0 \%$ in the semuloparin and placebo groups, respectively (absolute risk difference $+0.8 \%$; HR 1.40 ; 95\% CI 0.89-2.21). However, there were more patients with treatment-emergent bleeding events overall in the semuloparin group compared with the placebo group (20\% versus $16 \%$, respectively), including serious cases $(1.9 \%$ versus $1.5 \%) .{ }^{36}$ Rates of major bleeding were similar in both treatment groups $(1.2 \%$ versus $1.1 \%)$. Fatal bleeding occurred in two and four patients in the semuloparin and placebo groups, respectively. However, major bleeding into a critical area or organ, as included in a US Food and Drug Administration analysis, was observed in seven patients in the semuloparin group and no patients in the placebo group. These cases included two pericardial, one intraocular (resulting in retinal detachment), one splenic, and three intracranial bleeds, of which one case was fatal. ${ }^{37}$ Rates of all deaths during the overall study period (43.4\% versus $44.5 \%)^{35}$ and on-treatment deaths $(15.7 \% \text { versus } 15.9 \%)^{37}$ were similar in the two study groups.

In conclusion, semuloparin reduced the incidence of VTE in patients receiving chemotherapy for cancer, with sizable variation in the absolute benefit depending on tumor type and baseline VTE risk. Although there was no significant increase in overall major bleeding, there was a trend towards a higher risk of bleeding into a critical area or organ with semuloparin in comparison with placebo. No trend towards a survival benefit was noted.

\section{VTE prophylaxis in major abdominal surgery}

SAVE-ABDO ${ }^{36-38}$ was a randomized, active-controlled trial for the prevention of VTE in patients undergoing major abdominal surgery for indications other than disease of the liver, uterus, or prostate. Patients younger than 60 years of age had to have one of the following additional risk factors: cancer surgery, history of VTE, body mass index $\geq 30 \mathrm{~kg} / \mathrm{m}^{2}$, chronic heart failure, chronic respiratory failure, or inflammatory bowel disease. A total of 4413 patients were randomized 1:1 to receive either semuloparin $20 \mathrm{mg}$ subcutaneous once daily started postoperatively or enoxaparin $40 \mathrm{mg}$ subcutaneous once daily started preoperatively for a duration of 7-10 days after surgery, of which 3030 patients were assessable for efficacy. This trial failed to meet its primary efficacy endpoint of any VTE or all-cause death in a noninferiority comparison of semuloparin versus enoxaparin $(6.3 \%$ versus $5.5 \%$; odds ratio [OR] 1.16; 95\% CI 0.87-1.54; noninferiority margin 1.25). ${ }^{36,37}$ Rates of major VTE or all-cause deaths (secondary endpoint) were similar in the semuloparin and enoxaparin groups $(2.2 \%$ versus $2.3 \%$; OR $0.95 ; 95 \% \mathrm{CI}$ 0.61-1.49).

Eighty-one percent $(n=2451)$ of the primary efficacy population was composed of patients with cancer and undergoing oncological surgery. An exploratory analysis by the US Food and Drug Administration in the subgroup of patients with cancer showed a numerically higher proportion of subjects 
Table 2 Characteristics of old and new anticoagulants*

\begin{tabular}{|c|c|c|c|c|c|}
\hline & Parenteral anticoag & llants & & & \\
\hline Agent & Heparin sodium & $\mathrm{LMWH}^{\dagger}$ & Semuloparin & Fondaparinux & Idrabiotaparinux \\
\hline Source & Pig intestinal mucosa & Pig intestinal mucosa & Pig intestinal mucosa & Synthetic & Synthetic \\
\hline $\begin{array}{l}\text { Molecular } \\
\text { weight (Da) }\end{array}$ & $12,000-15,000$ & $3600-6500$ & 2000-3000 & 1728 & $\begin{array}{l}1727 \text { (idraparinux) + } \\
244 \text { (biotin) }\end{array}$ \\
\hline Target & $\begin{array}{l}\text { FXa }=\text { Flla } \\
(\text { I to I ratio) }\end{array}$ & $\begin{array}{l}\text { FXa }>\text { Flla } \\
\text { (2 to 8:I ratio) }\end{array}$ & $\begin{array}{l}\text { FXa }>\text { Flla } \\
(80: 1 \text { ratio })\end{array}$ & FXa only & FXa only \\
\hline Type of inhibition & Indirect (bind to AT) & Indirect (bind to AT) & Indirect (bind to AT) & Indirect (bind to AT) & Indirect (bind to AT) \\
\hline Bioavailability (\%) & 100 (IV) & $90-98$ (SC) & $98 \%(S C)$ & About I00 (SC) & About 100 (SC) \\
\hline $\mathrm{T}_{\max }$ & Few minutes & $2-3$ hours & $2-3$ hours & $30-60$ minutes & 4 hours \\
\hline Drug interactions & П & ף & П & I & ף \\
\hline Protein binding (\%) & High & Low & Low & Low & Very low \\
\hline Half-life & $0.5-1$ hour & $3-6$ hours & 16-20 hours & $|7-2|$ hours & 120 hours \\
\hline Metabolism & Depolymerization & $\begin{array}{l}\text { Desulfation, } \\
\text { depolymerization }(<10 \%)\end{array}$ & Not reported & Negligible & Negligible \\
\hline Renal excretion (\%) & Medium & High & High & 64-77 (unchanged) & High (unchanged) \\
\hline Biliary excretion (\%) & Medium & Low & Low & Negligible & Negligible \\
\hline Antidote & Protamine & Protamine (partially) & None & None & Avidin \\
\hline Monitoring test & aPTT & $\begin{array}{l}\text { Not required routinely } \\
\text { Anti-Xa assay }\end{array}$ & $\begin{array}{l}\text { Not required } \\
\text { routinely } \\
\text { Anti-Xa assay }\end{array}$ & $\begin{array}{l}\text { Not required } \\
\text { routinely } \\
\text { Anti-Xa assay }\end{array}$ & $\begin{array}{l}\text { Not required routinely } \\
\text { Anti-Xa assay }\end{array}$ \\
\hline Approval date & 1939 (EU, US) & $\begin{array}{l}\text { I } 985 \text { (EU, dalteparin) } \\
1993 \text { (US, enoxaparin) }\end{array}$ & Not yet approved & $\begin{array}{l}2000 \text { (US) } \\
2002 \text { (EU) }\end{array}$ & Not yet approved \\
\hline
\end{tabular}

Notes: †Ardeparin, bemiparin, certoparin, dalteparin, enoxaparin, nadroparin, parnaparin, reviparin, tinzaparin; ‡dicumarol (no longer available), warfarin, acenocoumarol, phenprocoumon; §inhibition of vitamin K epoxide reductase; "potential pharmacodynamic interactions with other drugs that alter haemostasis (eg, other anticoagulants, fibrinolytics, and antiplatelet drugs).

Abbreviations: ACT, activated coagulation time; aPTT, activated partial thromboplastin time; AT, antithrombin; inh/ind, inhibitors/inducers; CYP, cytochrome P450; EU, European Union; INR, international normalized ratio; IV, intravenous; LMWH, low molecular weight heparin; NA, data not available; PD, pharmacodynamics; P-gp, P-glycoprotein; PK, pharmacokinetics; SC, subcutaneous; $T_{\max }$, time to maximum concentration; US, United States; VKA, vitamin K antagonist.

with VTE events in the semuloparin arm than the enoxaparin $\operatorname{arm}(7.1 \%$ versus $5.9 \%$; OR 1.23 ; 95\% CI $0.89-1.69) .{ }^{37}$ In the overall study population, semuloparin was associated with less clinically relevant bleeding $(2.9 \%$ versus $4.5 \%$; OR 0.63 ; $95 \%$ CI $0.46-0.87)$ and less major bleeding (4.1\% versus $5.7 \%$; OR $0.71 ; 95 \%$ CI $0.54-0.93$ ) than enoxaparin.

\section{Idraparinux sodium}

Idraparinux sodium (SR34006, Sanofi-Aventis and Organon Pharmaceuticals Inc, Roseland, NJ, USA), investigated in the SANORG 34006 trial, is a long-acting synthetic molecule, developed based on the native pentasaccharide sequence that binds to antithrombin, thus indirectly inhibiting $\mathrm{FXa}$ activity. ${ }^{39,40}$ Idraparinux is almost completely absorbed after subcutaneous injection and the time to maximum concentration is about 4 hours after subcutaneous administration. It has a half-life of 120 hours in healthy subjects ${ }^{41}$ and 66 days after multiple doses in patients, ${ }^{42}$ allowing for once-weekly administration. It is excreted unchanged via the kidneys. Therefore, there is a risk of accumulation in patients with renal insufficiency. The anticoagulant effect may persist for 3-4 months after termination of therapy. ${ }^{43}$

\section{Acute and long-term treatment of deep vein thrombosis}

In a randomized, open-label, noninferiority Phase III trial in patients with deep vein thrombosis (van Gogh-DVT, $\mathrm{n}=2904$ ), idraparinux $2.5 \mathrm{mg}$ once weekly was as effective as standard therapy (heparin followed by an adjusted-dose vitamin $\mathrm{K}$ antagonist) administered for 3-6 months. ${ }^{44}$ The incidence of recurrence at day 92 was $2.9 \%$ in the idraparinux group as compared with $3.0 \%$ in the standard therapy group (OR $0.98 ; 95 \%$ CI $0.63-1.50$ ), a result that satisfied the prespecified noninferiority requirement (upper limit of the 95\% CI for the OR for documented symptomatic recurrent VTE $<2$ ). At 6 months, clinically relevant bleeding rates were similar $(8.3 \%$ versus $8.1 \%)$. A post hoc analysis of the subgroup of patients with cancer $(n=421)$ showed that idraparinux was as effective as a vitamin $\mathrm{K}$ antagonist with respect to recurrent VTE (idraparinux $2.5 \%$ versus standard 


\begin{tabular}{|c|c|c|c|c|c|}
\hline \multicolumn{6}{|l|}{ Oral anticoagulants } \\
\hline Vitamin K antagonists ${ }^{\ddagger}$ & Dabigatran etexilate & Rivaroxaban & Apixaban & Edoxaban & Betrixaban \\
\hline Synthetic & Synthetic & Synthetic & Synthetic & Synthetic & Synthetic \\
\hline About 1000 & 628 & 436 & 460 & 548 & 452 \\
\hline FII, VII, IX, X, protein C, S & Thrombin & $\mathrm{FXa}$ & FXa & $\mathrm{FXa}$ & $\mathrm{FXa}$ \\
\hline Indirect ${ }^{\S}$ & Direct & Direct & Direct & Direct & Direct \\
\hline$>60$ & 6.5 & $80-100$ & 50 & $50 \%$ & $34 \%$ \\
\hline I-3 hours & $0.5-2$ hours & $2-4$ hours & $3-4$ hours & 1.5 hours & 2.5 hours \\
\hline $\begin{array}{l}\text { Dietary vitamin } \mathrm{K} \text {, multiple } \\
\text { drugs and foods }\end{array}$ & $\begin{array}{l}\text { P-gp inh/ind, } \\
\text { proton pump inh }\end{array}$ & $\begin{array}{l}\text { Potent P-gp and } \\
\text { CYP3A4 inh/ind }\end{array}$ & $\begin{array}{l}\text { Potent P-gP and } \\
\text { CYP3A4 inh/ind" }\end{array}$ & $\begin{array}{l}\text { Potent P-gP } \\
\text { inh/ind }\end{array}$ & $\begin{array}{l}\text { Potent P-gp inh/ } \\
\text { ind }\end{array}$ \\
\hline About 99 & 35 & $92-95$ & 87 & $40-60$ & 60 \\
\hline $\begin{array}{l}\text { 8-1I hours (acenocoumarol); } \\
36-42 \text { hours (warfarin) }\end{array}$ & 14-17 hours & $7-12$ hours & 12 hours & $6-11$ hours & 19 hours \\
\hline $\begin{array}{l}\text { CYP2C9/19 (acenocoumarol); } \\
\text { CYP2C9/IA2/3A4 (warfarin) }\end{array}$ & $\begin{array}{l}\text { Glucuronidation } \\
(<10 \%)\end{array}$ & CYP3A4 > CYP2J2 & $\begin{array}{l}\text { CYP3A4/5 > CYP2IA2, } \\
\text { SC8, 2C9/19, 2J2 }\end{array}$ & Hydrolysis & $\begin{array}{l}\text { Hydrolysis > } \\
\text { demethylation }\end{array}$ \\
\hline 92 & 85 (unchanged) & 66 & 27 & $36-45$ & $6-13$ \\
\hline 8 & 6 & 28 & 25 & NA & $82-89$ \\
\hline Vitamin $\mathrm{K}$ & None & None & None & None & None \\
\hline INR & $\begin{array}{l}\text { Not required routinely } \\
\text { Diluted thrombin time }\end{array}$ & $\begin{array}{l}\text { Not required routinely } \\
\text { Anti-Xa assay }\end{array}$ & $\begin{array}{l}\text { Not required routinely } \\
\text { Anti-Xa assay }\end{array}$ & NA & NA \\
\hline 1941 & 2008 (EU) & 2008 (EU) & 2011 (EU) & 2011 (Japan) & Not yet \\
\hline (US, dicumarol) & 2010 (US) & 2011 (US) & 2013 (US) & & approved \\
\hline I 953 (EU, phenprocoumon) & & & & & \\
\hline
\end{tabular}

therapy $6.4 \%$; HR 0.39 ; 95\% CI $0.14-1.11$ ), with similar rates of bleeding events (OR 0.89; 95\% CI 0.50-1.59) and death (HR 0.99; 95\% CI 0.66-1.48). ${ }^{45}$

\section{Acute and long-term treatment of pulmonary embolism}

In patients with pulmonary embolism (van Gogh-PE trial, $\mathrm{n}=2215$ ), idraparinux was less effective than standard therapy. ${ }^{44}$ The incidence of recurrence at day 92 was $3.4 \%$ in the idraparinux $2.5 \mathrm{mg}$ once weekly group and $1.6 \%$ in the standard therapy group (OR 2.14; 95\% CI 1.21-3.78). Clinically relevant bleeding rates at 6 months were similar (7.7\% versus 9.7\%) and death rates were higher with idraparinux than with standard therapy $(6.4 \%$ versus $4.4 \% ; P=0.04)$. A total of 320 patients had a history of cancer. No subgroup analysis of patients with cancer is available from the van Gogh-PE study.

\section{Extended treatment of VTE}

During a 6-month extension of thromboprophylaxis (van Gogh-Extension trial, $\mathrm{n}=1215),{ }^{46}$ idraparinux $2.5 \mathrm{mg}$ once weekly was more effective than placebo in preventing recurrent VTE (1.0\% versus 3.7\%; OR 0.27; 95\% CI 0.11-0.66; $P=0.002)$ but was associated with an excessive risk of major hemorrhage $(1.9 \%$ versus $0 \% ; P<0.001)$, including three fatal intracranial bleeds. A total of 120 patients had a history of cancer, but no efficacy or safety data were reported for this subgroup.

Follow-up data from the van Gogh clinical trials suggests that the very long elimination half-life of idraparinux may explain the increase in bleeding complications in the extension trial. ${ }^{47}$ Clinical development of idraparinux, which has no antidote, was halted in favor of idrabiotaparinux, for which an antidote (avidin) is readily available.

\section{Idrabiotaparinux}

Idrabiotaparinux (biotinylated idraparinux, SSR126517E, Sanofi-Aventis) is a long-acting synthetic pentasaccharide with pharmacokinetic and anticoagulant properties similar to those of the previous compound, idraparinux (Table 2). ${ }^{40-42}$ Unlike idraparinux, the anticoagulant effect of 


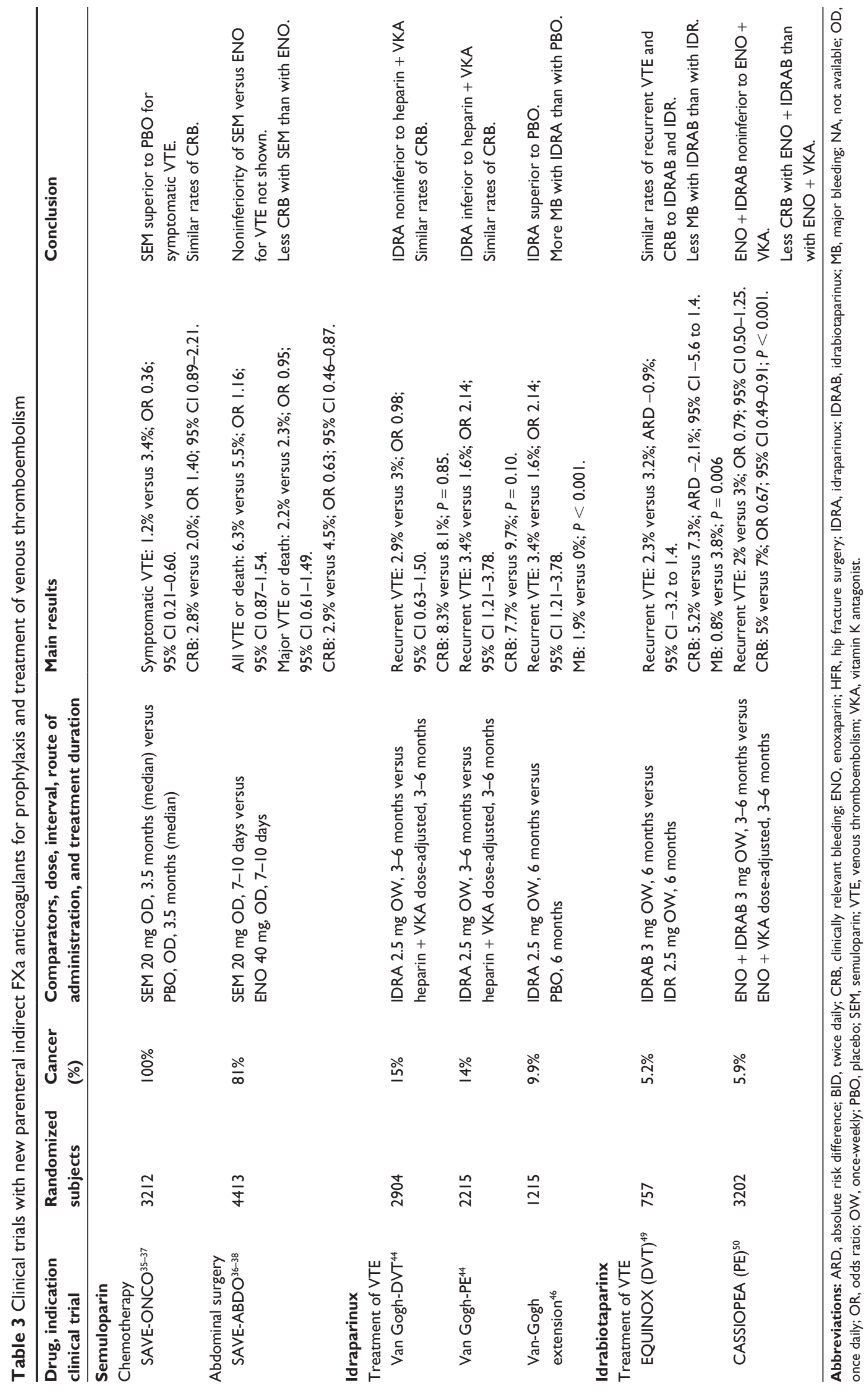


idrabiotaparinux can be rapidly neutralized because of its binding to the biotin moiety following intravenous infusion of avidin (EP5001), an egg-derived protein. ${ }^{48}$ The main results of the studies using idrabiotaparinux in the treatment of VTE are summarized in Table 3 and are discussed below. No clinical studies are currently ongoing with this compound.

\section{Acute and long-term treatment of deep vein thrombosis}

The EQUINOX study ${ }^{49}$ was a randomized double-blind trial comparing the efficacy and safety of idrabiotaparinux $3 \mathrm{mg}$ and idraparinux $2.5 \mathrm{mg}$, each given subcutaneously once weekly for 6 months in patients with acute symptomatic deep vein thrombosis (Table 3). A total of 757 patients underwent randomization, of whom $5.2 \%(n=39)$ had active cancer. No efficacy or safety data were reported in this subpopulation. In the overall population, rates of recurrent VTE and of fatal or nonfatal pulmonary embolism were similar between idrabiotaparinux (2.3\%, nine of 386 patients) and idraparinux (3.2\%, 12 of 371 patients) at 6 months (absolute risk difference $-0.9 \% ; 95 \% \mathrm{CI}-3.2$ to 1.4$)$. The study was not powered for efficacy, so no definitive conclusions can be made in this regard. There was less clinically relevant bleeding (5.2\% versus $7.3 \%)$ and less major bleeding $(0.8 \%$ versus $3.8 \%$ ) with idrabiotaparinux than with idraparinux (Table 3). The finding of lower bleeding rates with idrabiotaparinux than with idraparinux is intriguing, given that both drugs exerted similar inhibition of FXa activity. This difference cannot be explained by the administration of avidin, because it occurred in only three patients during the 6-month study period.

\section{Long-term treatment of pulmonary embolism}

CASSIOPEA $^{50}$ was a randomized, double-blind, doubledummy, noninferiority trial that compared the efficacy and safety of idrabiotaparinux versus warfarin in the long-term treatment of symptomatic pulmonary embolism. Patients were randomized to receive initial treatment for acute pulmonary embolism of enoxaparin $1 \mathrm{mg} / \mathrm{kg}$ subcutaneously twice daily for 5-10 days, followed by idrabiotaparinux (starting dose $3 \mathrm{mg}$ subcutaneously once weekly) or enoxaparin $1 \mathrm{mg} / \mathrm{kg}$ subcutaneously twice daily or 5-10 days, overlapping with and followed by dose-adjusted warfarin (INR 2-3). These regimens lasted 3 or 6 months depending on clinical presentation. A total of 3202 patients were enrolled, of whom $5.9 \%$ (190 patients) had cancer present or treated in the last 6 months. No subgroup analysis for the cancer patients is available. Recurrent VTE at 99 days (main outcome) was similar in both treatment groups ( $2 \%$ versus $3 \%$; OR 0.79 ; 95\% CI 0.50-1.25; prespecified noninferiority limit 2.0; noninferiority $P=0.0001$ ). There were fewer clinically relevant bleeding episodes (main safety outcome) in patients in the enoxaparin-idrabiotaparinux group than in the enoxaparinwarfarin group (5\% versus 7\%: OR 0.67; 95\% CI 0.49-0.91; $P=0.0098)$. Differences in outcome were similar in patients treated to 6 months. In conclusion, idrabiotaparinux could provide an alternative to warfarin for the long-term treatment of pulmonary embolism, and seems to be associated with reduced bleeding.

\section{Novel oral direct Factor $\mathbf{X a}$ inhibitors Rivaroxaban}

Rivaroxaban (BAY 59-7939, Xarelto ${ }^{\circledR}$, Bayer HealthCare) is an oxazolidinone derivative with a molecular weight of $436 \mathrm{Da}$ and high selectivity for direct inhibition of FXa (Table 2). ${ }^{51}$ In healthy subjects, rivaroxaban was well tolerated, with a predictable pharmacological profile for single and repeated doses. ${ }^{51,52}$ Maximum inhibition of FXa activity was $75 \%$ after a single oral dose of $40 \mathrm{mg} .{ }^{53}$ Peak plasma levels are reached in about 3 hours. Half-life ranges from a mean of 7 (5-9) hours in healthy volunteers to 12 (11-13) hours in elderly people. Rivaroxaban is metabolized in the liver by cytochrome P450 (CYP3)A4 and, to a lesser extent, via CYP2J2. ${ }^{54}$ Rivaroxaban is mainly excreted by the kidneys (Table 2) and to a lesser extent by the bile and intestines via the P-glycoprotein transport system. Caution must be exercised in patients receiving treatment with potent inhibitors of both CYP3A4 and P-glycoprotein, such as ketoconazole or ritonavir. ${ }^{55}$

Rivaroxaban is currently approved in the European Union, the US, and other countries for VTE prophylaxis after total hip replacement or total knee arthroplasty on the basis of the RECORD1-4 studies, ${ }^{56-59}$ as well as for stroke prevention in atrial fibrillation based on the ROCKET-AF clinical trial. ${ }^{60}$ Rivaroxaban is also approved in several regions for the acute and long-term treatment of VTE as a result of the positive results obtained in the EINSTEIN studies. ${ }^{61,62}$ A pilot study (Catheter 2) is currently investigating rivaroxaban for the treatment of central line-associated blood clots in cancer patients $(n=72$, ClinicalTrials.gov ID, NCT01708850).

The main results of the completed Phase III studies for nonsurgical VTE prophylaxis or treatment of VTE (Tables 4 and 5, respectively), are discussed below, paying special attention to data available for cancer patients. 


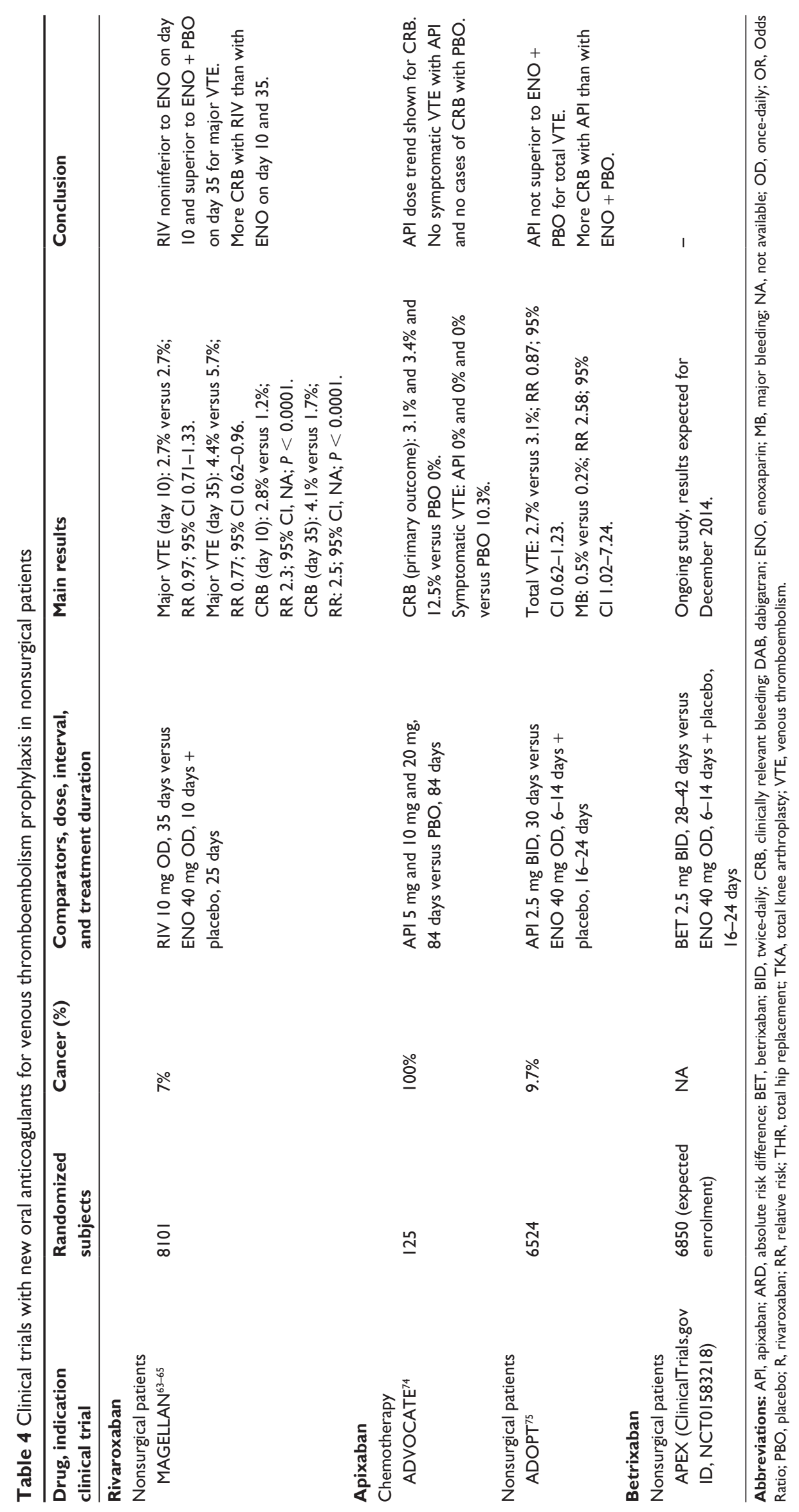




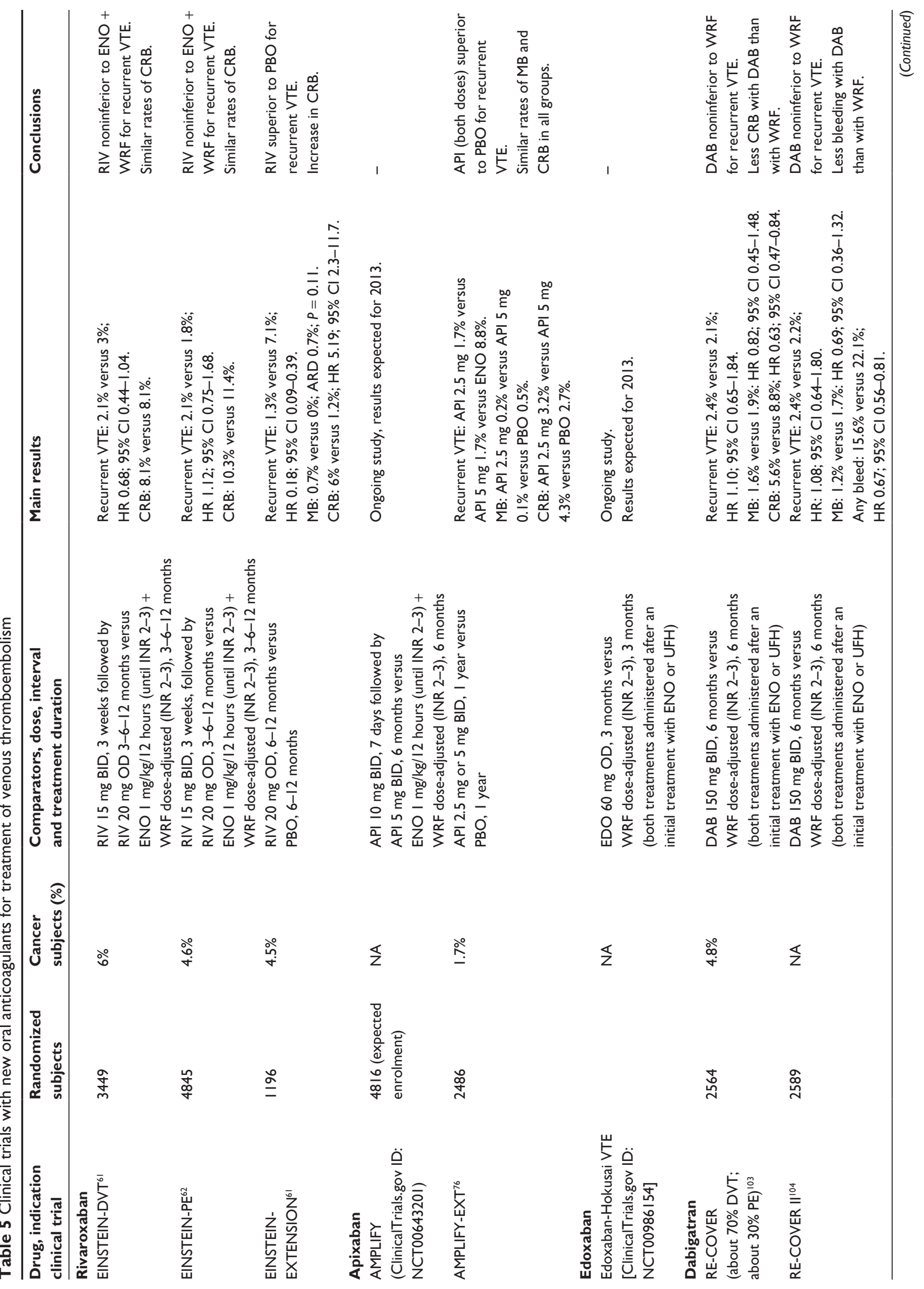




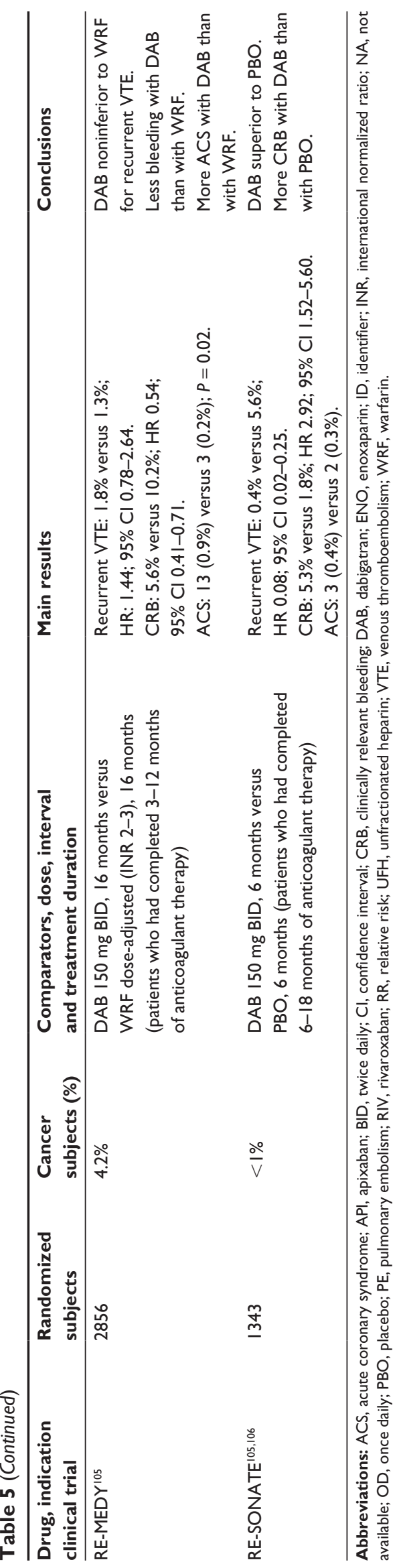

\section{VTE prophylaxis in medical patients}

The MAGELLAN study ${ }^{63-65}$ was a multinational, multicenter, randomized, double-blind controlled trial in which medical patients aged $\geq 40$ years hospitalized for acute medical illness with decreased level of mobility were randomized to oral rivaroxaban $10 \mathrm{mg}$ once daily for 35 days or enoxaparin $40 \mathrm{mg}$ for 10 days followed by placebo until completion of 35 days of treatment. A total of 8101 patients were randomized, of whom 584 (7\%) had concomitant cancer. The primary efficacy outcome (composite of asymptomatic proximal deep vein thrombosis of the lower limbs detected by ultrasonography, proximal or distal symptomatic deep vein thrombosis, or symptomatic pulmonary embolism) occurred in $2.7 \%$ of patients in each group (relative risk [RR] 0.97; 95\% CI 0.71-1.33; RR noninferiority margin 1.5 ; noninferiority $P$ value $=0.0025$ ) on day 10 , and in $4.4 \%$ of patients on rivaroxaban and in $5.7 \%$ of patients on enoxaparin followed by placebo (RR $0.77 ; 95 \%$ CI 0.62-0.96; superiority $P$ value 0.0211 ) on day 35 .

Rivaroxaban demonstrated more clinically relevant bleeding (main safety outcome) than enoxaparin on day $10(2.8 \%$ versus $1.2 \%$; RR 2.3 ; 95\% CI 1.63-3.17; $P<0.0001)$ and day 35 (4.1\% versus $1.7 \%$; RR 2.5; 95\% CI 1.85-3.25; $P<0.0001)$. Major bleeding was also more frequent with rivaroxaban than with enoxaparin on day 10 ( $0.6 \%$ versus $0.3 \%$; RR $2.2 ; 95 \%$ CI $1.07-4.45 ; P=0.0318)$ and day $35(1.1 \%$ versus $0.4 \%$; RR 2.9; $95 \%$ CI $1.60-5.15 ; P<0.001)$. Death rates were similar in both groups by day 35 (5.1\% versus $4.8 \%)$.

In subgroup analyses, extended thromboprophylaxis with rivaroxaban showed a nonsignificant trend towards less efficacy than short-term enoxaparin in patients with active cancer on day 35 (9.9\% versus $7.4 \%$; RR 1.34; $95 \%$ CI $0.71-2.54),{ }^{64,65}$ while clinically relevant bleeding was more frequent with rivaroxaban than with enoxaparin plus placebo on day 35 (5.4\% versus $1.7 \%,{ }^{64}$ RR 3.16 ; 95\% CI 1.17-8.50; authors' calculation). In conclusion, rivaroxaban was noninferior to enoxaparin for short-term thromboprophylaxis and superior to enoxaparin plus placebo for extended thromboprophylaxis. The efficacy of rivaroxaban was consistent across all covariates analyzed, with the exception of active cancer. ${ }^{65}$ Bleeding rates were significantly increased with rivaroxaban in patients with cancer and in the overall study population.

\section{Acute and long-term treatment of deep vein thrombosis and pulmonary embolism}

The EINSTEIN-DVT study ${ }^{61}$ was an open-label, randomized, event-driven, noninferiority study that compared oral rivaroxaban alone (15 $\mathrm{mg}$ twice daily for 3 weeks, followed 
by $20 \mathrm{mg}$ once daily) subcutaneous enoxaparin followed by a vitamin $\mathrm{K}$ antagonist (either warfarin or acenocoumarol) for 3, 6, or 12 months in patients with acute, symptomatic deep vein thrombosis. The study included 3449 patients, of whom 207 (6\%) had active cancer. Rivaroxaban had noninferior efficacy for the primary outcome of symptomatic recurrent VTE (2.1\% versus 3.0\%; HR 0.68; 95\% CI 0.44-1.04; noninferiority $P$ value $<0.001)$. Clinically relevant bleeding (primary safety outcome) occurred in $8.1 \%$ of patients in each group (Table 5). In cancer patients, both groups had similar rates of recurrent VTE (3.4\% versus $5.6 \%)$ and clinically relevant bleeding $(14.4 \%$ versus $15.9 \%$ ).

The EINSTEIN-PE study ${ }^{62}$ was a randomized, open-label, event-driven, noninferiority trial involving 4832 patients who had acute symptomatic pulmonary embolism with or without deep vein thrombosis. The authors compared rivaroxaban (15 mg twice daily for 3 weeks, followed by $20 \mathrm{mg}$ once daily) with standard therapy of enoxaparin followed by an adjusted-dose vitamin $\mathrm{K}$ antagonist for 3, 6, or 12 months. A total of 4833 patients underwent randomization, of whom 223 (4.6\%) had active cancer. Rivaroxaban was noninferior to standard therapy for the primary outcome of symptomatic recurrent VTE (2.1\% versus $1.8 \%$; HR 1.12; 95\% CI $0.75-1.68$; noninferiority margin $2.0 ; P=0.003$ ). The primary safety outcome occurred at similar rates in the rivaroxaban and standard therapy groups $(10.3 \%$ versus $11.4 \%$, respectively; HR 0.90 ; 95\% CI 0.76-1.07; $P=0.23$ ). Major bleeding rates with rivaroxaban were lower than with standard treatment (1.1\% versus $2.2 \%$; HR 0.49 ; $95 \%$ CI $0.31-0.79 ; P=0.003)$. Deaths were numerically higher with rivaroxaban than with standard treatment ( 58 versus 50 ; $P=0.53)$. In cancer patients, both groups had similar rates of recurrent VTE (1.8\% versus $2.8 \%$ ) and clinically relevant bleeding (12.3\% versus $9.3 \%)$.

The overall data from the EINSTEIN-DVT and EINSTEIN-PE studies suggest that the single-drug approach to the initial and long-term treatment of deep vein thrombosis or pulmonary embolism with rivaroxaban is at least as effective and safe as standard treatment with enoxaparin and a vitamin $\mathrm{K}$ antagonist. We have conducted a pooled analysis of both studies comparing rivaroxaban and standard treatment in the subgroup of patients with cancer (Figure 2), based on subgroup data reported in the original publications. ${ }^{61,62}$ The pooled analysis suggests that the treatment groups had a similar risk of recurrent VTE (RR 0.62; 95\% CI 0.22-1.74) and clinically relevant bleeding (RR 1.07; 95\% CI 0.65-1.75) in cancer patients.

\section{Extended treatment of deep vein thrombosis and pulmonary embolism}

The EINSTEIN-extension study ${ }^{61}$ was a double-blind, randomized, event-driven, superiority study that compared rivaroxaban $20 \mathrm{mg}$ once daily with placebo for an additional 6 or 12 months in patients who had completed 6-12 months of treatment for VTE. The study included 1197 patients, of whom 54 (4.5\%) had active cancer. Rivaroxaban had superior efficacy compared with placebo for the primary endpoint of symptomatic recurrent VTE (1.3\% versus $7.1 \%$; HR 0.18; 95\% CI 0.09-0.39; $P<0.001)$. Major bleeding (the main safety outcome) occurred in four $(0.7 \%)$ patients in the rivaroxaban group versus none in the placebo group $(P=0.11)$. Clinically relevant bleeding was more frequent with rivaroxaban than with placebo (6\% versus $1.2 \%$; HR 5.19; 95\% CI 2.3-11.7). Three patients died during the study (one in the rivaroxaban group and two in the placebo group).

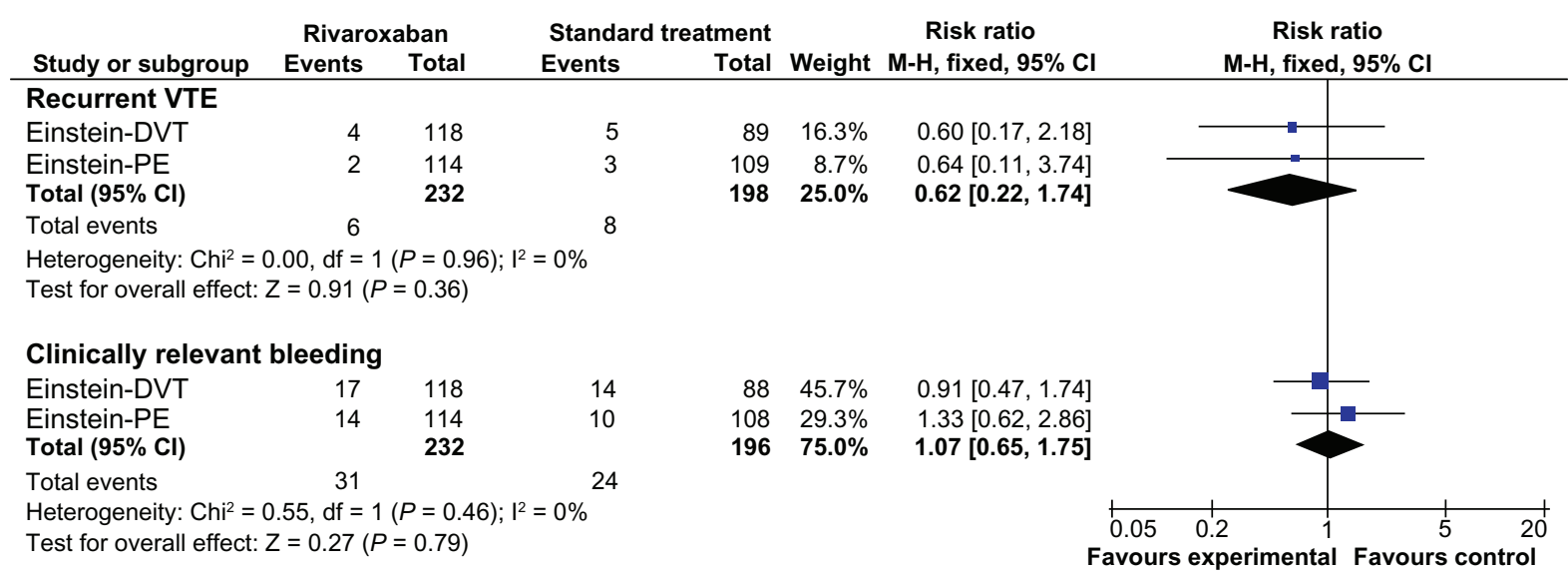

Figure 2 Pooled analysis of recurrent venous thromboembolism and clinically relevant bleeding in patients with cancer included in the EINSTEIN-DVT and EINSTEIN-PE studies. 
No subgroup analysis in cancer patients is available for this study.

\section{Apixaban}

Apixaban (BMS-562247-01, Eliquis ${ }^{\circledR}$, Bristol-Myers Squibb) is an oral, direct, and highly selective FXa inhibitor. Apixaban was effective in the prevention of experimental thrombosis at doses that preserve hemostasis in rabbits. ${ }^{66}$ In humans, apixaban is absorbed relatively rapidly, with peak concentrations achieved approximately 3 hours post-dosing, and a mean terminal half-life ranging from 8 to 15 hours. ${ }^{67}$ Apixaban is metabolized mainly via CYP3A4/5, with minor contributions from CYP1A2, 2C8, 2C9, 2C19, and 2J2 ${ }^{68}$ Apixaban is also a substrate of the transport proteins, P-glycoprotein and breast cancer resistance protein. ${ }^{68}$ Drug-drug interaction studies show a two-fold increase in exposure to apixaban after administration of potent inhibitors of CYP3A4 and P-glycoprotein (eg, ketoconazole), while the exposure to apixaban decreases by $50 \%$ after concomitant administration of potent inducers of CYP3A4 and P-glycoprotein (eg, rifampicin). Therefore, in these clinical situations, apixaban should be administered with caution. ${ }^{67}$ Apixaban has multiple routes of elimination. Renal excretion of apixaban accounts for approximately $27 \%$ of total clearance (Table 2). ${ }^{69}$

Apixaban is currently authorized in the European Union and other regions for VTE prophylaxis after total hip replacement or total knee arthroplasty on the basis of the ADVANCE1-3 studies, ${ }^{70-72}$ as well as for stroke prevention in atrial fibrillation based on the ARISTOTLE study. ${ }^{73}$ The main results of the completed Phase II-III studies for nonsurgical VTE prophylaxis or treatment of VTE (Tables 4 and 5, respectively) are discussed below, paying special attention to data available from cancer patients.

\section{VTE prevention in medical patients on chemotherapy}

ADVOCATE $^{74}$ was a Phase II pilot study evaluating whether apixaban would be well tolerated and acceptable in cancer patients receiving chemotherapy. The study enrolled patients receiving either first-line or second-line chemotherapy for advanced or metastatic breast $(n=32)$, pancreatic $(n=15)$, gastrointestinal $(n=16)$, lung $(n=12)$, ovarian $(n=2)$, or prostate cancers $(n=13)$, myeloma/ lymphoma $(n=21)$, and cancers of unknown origin. Use of the study drug began within 4 weeks of the start of chemotherapy. Patients at moderate to high risk of bleeding were excluded (eg, patients with prolonged coagulation times or receiving antiplatelet therapy, bevacizumab, or other therapies with potential to cause bleeding). A total of 125 patients were randomized to receive once-daily doses of apixaban $5 \mathrm{mg}(\mathrm{n}=32), 10 \mathrm{mg}(\mathrm{n}=30), 20 \mathrm{mg}$ $(n=33)$, or placebo $(n=30)$ in a double-blind manner for 12 weeks. In these groups, the number of clinically relevant bleeding episodes (main outcome) were one $(3.1 \%)$, one $(3.4 \%)$, four $(12.5 \%)$, and one $(3.4 \%)$. The corresponding number of major bleeding episodes was 0,0 , two, and one, respectively. There were no fatal bleeding episodes. No subjects in any of the apixaban groups and three patients in the placebo group (10.3\%) developed symptomatic VTE. Three patients died (apixaban $5 \mathrm{mg}$, heart failure; placebo, heart failure and progressive cancer). There was a strong linear dose-response effect across the apixaban dose groups, with prothrombin fragments F1 and F2 decreasing by $1.9 \%(95 \%$ CI $0.7-3.1 ; P=0.004)$ for each milligram of drug. In conclusion, apixaban $5 \mathrm{mg}$ and $10 \mathrm{mg}$ once daily were well tolerated in this study and associated with a low risk for VTE, thus supporting further study of apixaban in Phase III trials to prevent VTE in cancer patients receiving chemotherapy. These findings are limited due to the small sample size, the lack of screening for asymptomatic events, and the exclusion of patients at moderate to high bleeding risk. No further confirmatory studies are currently ongoing with apixaban in this setting.

\section{VTE prophylaxis in medical patients}

The ADOPT study ${ }^{75}$ was a double-blind, double-dummy, placebo-controlled trial in which acutely ill hospitalized medical patients were randomly assigned to receive apixaban orally at a dose of $2.5 \mathrm{mg}$ twice daily for 30 days or subcutaneous enoxaparin at a dose of $40 \mathrm{mg}$ once daily for 6-14 days. A total of 6528 subjects underwent randomization, of whom $632(9.7 \%)$ had a history of cancer (active or past). The primary efficacy outcome (major VTE or death on day 30) occurred at a similar rate in the apixaban extended-course and enoxaparin short-term course groups $(2.71 \%$ versus $3.06 \%$; RR 0.87 ; 95\% CI 0.62-1.23; $P=0.44$ ). By day 30 , major bleeding rates were low, but higher in the apixaban group than in the enoxaparin group $(0.47 \%$ versus $0.19 \%$; RR 2.58 ; 95\% CI 1.02-7.24; $P=0.04)$. In conclusion, in medically ill patients, an extended course of thromboprophylaxis using apixaban was not superior to a shorter course using enoxaparin and was associated with significantly more major bleeding events than was enoxaparin. No subgroup analyses in patients with cancer are currently available. 


\section{Extended treatment of deep vein thrombosis and pulmonary embolism}

The AMPLIFY-EXT study ${ }^{76}$ was a randomized, doubleblind trial that compared two doses of apixaban $(2.5 \mathrm{mg}$ and $5 \mathrm{mg}$ twice daily) with placebo for one additional year in patients with VTE who had completed 6-12 months of anticoagulation therapy. A total of 2486 patients underwent randomization, of whom 2482 were included in the intentionto-treat analyses. Of these, $42(1.7 \%)$ had active cancer at baseline, but no efficacy or safety data have been reported in this subpopulation. Symptomatic recurrent VTE occurred less often in patients who were receiving apixaban $2.5 \mathrm{mg}$ $(1.7 \%)$ or $5 \mathrm{mg}(1.7 \%)$ than in patients who were receiving placebo $(8.8 \%$, RR of apixaban $2.5 \mathrm{mg}$ versus placebo 0.19 , 95\% CI 0.11-0.33; RR of apixaban $5 \mathrm{mg}$ versus placebo 0.20 , 95\% CI 0.11-0.34). The rates of major bleeding (main safety outcome) were very low, and were similar in the three groups $(0.2 \%$ versus $0.1 \%$ versus $0.5 \%$, Table 5$)$. The rates of clinically relevant bleeding were $3.2 \%, 4.3 \%$, and $2.7 \%$ (RR of apixaban $2.5 \mathrm{mg}$ versus placebo $1.20,95 \%$ CI $0.69-2.10$; RR of apixaban $5 \mathrm{mg}$ versus placebo 1.62, 95\% CI 0.96-2.73). In conclusion, extended anticoagulation with apixaban reduced the risk of recurrent VTE without significantly increasing the rate of major or clinically relevant bleeding.

\section{Acute and long-term treatment of deep vein thrombosis and pulmonary embolism}

A pivotal Phase III trial is ongoing to assess a singledrug approach with apixaban versus standard therapy for the acute and long-term treatment of VTE (AMPLIFY study, $\mathrm{n}=4816$ patients, www.clinicaltrials.gov ID, NCT00643201, Table 5).

\section{Edoxaban}

Edoxaban (DU-176b, Lixiana ${ }^{\circledR}$, Daiichi-Sankyo), the free form of edoxaban tosilate hydrate, is a novel oral direct FXa inhibitor. ${ }^{77}$ In animal models, edoxaban inhibited venous thrombosis to an extent comparable with that of warfarin and enoxaparin, and the bleeding tendency was low. ${ }^{78}$ Edoxaban is rapidly absorbed following oral administration, with a time to peak plasma concentrations of 1-2 hours. ${ }^{79}$ Terminal elimination half-life ranges from 5.8 to 10.7 hours. Approximately $36 \%-45 \%$ of the dose administered is cleared through the kidneys (Table 2), and dose adjustment is needed in patients with renal impairment, low body weight, and/or older age. ${ }^{79,80}$ Edoxaban is mainly metabolized through hydrolysis, and CYP enzymes appear to have an insignificant role in its metabolism. ${ }^{81} \mathrm{P}$-glycoprotein inhibitors are expected to increase the bioavailability of edoxaban by inhibition of P-glycoprotein in the intestine, and a reduced dose should be considered. ${ }^{80}$

Edoxaban tosilate hydrate has been marketed in Japan since 2011 for the prevention of VTE in patients undergoing major orthopedic surgery ${ }^{80}$ on the basis of the results of the pivotal STARS studies. ${ }^{82-85}$ The compound has also shown promising results in a Phase IIb study in patients with nonvalvular atrial fibrillation. ${ }^{86}$ A confirmatory study (ENGAGE AF-TIMI 48 study) ${ }^{87}$ is underway in this indication (ClinicalTrials.gov ID, NCT00781391). An additional pivotal study is ongoing in the long-term treatment of deep vein thrombosis and pulmonary embolism (Edoxaban Hokusai-VTE study; $\mathrm{n}=8250$ patients, Table 5). However, one of the exclusion criteria is patients with active cancer for whom long-term treatment with LMWH is anticipated (ClinicalTrials.gov ID, NCT00986154). The results are expected in 2013. No specific clinical studies in cancer patients are currently ongoing with edoxaban.

\section{Betrixaban}

Betrixaban (PRT-054021, Portola Pharmaceuticals, South San Francisco, CA) is an oral direct FXa inhibitor. ${ }^{88}$ Betrixaban has demonstrated antithrombotic activity in animal models of thrombosis, and inhibited generation of thrombin in human blood at concentrations that may prevent VTE in humans. ${ }^{89}$ Following oral administration, bioavailability is $34 \%$ and the half-life is 19 hours, which allows once-daily dosing. Betrixaban is not a substrate for major CYP enzymes, ${ }^{90}$ but is a substrate for efflux proteins, including P-glycoprotein (Table 2). The major biotransformation pathway for betrixaban is hydrolysis and, to a lesser extent, demethylation. ${ }^{90}$ It is excreted almost unchanged in bile $(82 \%-89 \%)$ and urine $(6 \%-13 \%){ }^{91}$

The compound has shown promising results in dosefinding studies for VTE prophylaxis in patients undergoing total knee arthroplasty (EXPERT study) ${ }^{91}$ and for stroke prevention in atrial fibrillation (EXPLORE-Xa), ${ }^{92}$ but it has not been developed further in these indications. The Phase III pivotal APEX study is evaluating extended-duration oral betrixaban $80 \mathrm{mg}$ once daily (for 28-42 days) with standard of care subcutaneous enoxaparin $40 \mathrm{mg}$ once daily (for 6-14 days) for hospital and postdischarge prevention of VTE in acutely ill medical patients 
(ClinicalTrials.gov ID, NCT01583218). Concomitant cancer is not an exclusion criterion, and probably a subset of patients recruited will have cancer, in line with MAGELLAN ${ }^{63-65}$ and ADOPT. ${ }^{75}$ The global trial is expected to enroll approximately 6850 patients and is to be completed in December 2014 (Table 4). Portola is developing in parallel a universal antidote for Factor Xa inhibitor anticoagulants known as PRT064445, which is currently in Phase II in 144 healthy volunteers (ClinicalTrials.gov ID, NCT01758432). No specific clinical studies in patients with cancer are currently ongoing with betrixaban.

\section{Novel direct oral thrombin inhibitors \\ Dabigatran etexilate}

Dabigatran etexilate (BIBR 1048, Pradaxa ${ }^{\circledR}$, Boehringer Ingelheim) is a small molecule prodrug. ${ }^{93}$ After oral administration, dabigatran etexilate is rapidly absorbed and converted to its active metabolite, dabigatran (BIBR 953 $\mathrm{ZW}$ ), by esterase-catalyzed hydrolysis in plasma and in the liver. Dabigatran is a potent, competitive, direct thrombin inhibitor. The absolute bioavailability of dabigatran following oral administration of dabigatran etexilate is approximately $6.5 \%$ (Table 2). ${ }^{94}$ Maximum plasma concentrations are reached within 0.5 and 2 hours of oral administration, ${ }^{94}$ but are delayed up to 6 hours if the oral dose is given early after surgery. ${ }^{95}$ It is eliminated primarily unchanged in the urine (85\%, Table 2). ${ }^{96}$ Dabigatran exposure is increased approximately 2.7 -fold to 6-fold in moderate to severe renal insufficiency, respectively. ${ }^{97}$ Dose adjustment is needed in moderate renal insufficiency, while it is contraindicated in severe renal insufficiency. ${ }^{97}$ Concomitant treatment with dabigatran and quinidine, a potent P-glycoprotein inhibitor, is contraindicated, while caution should be exercised with other strong P-glycoprotein inhibitors like verapamil or clarithromycin. Potent P-glycoprotein inducers, such as rifampicin or St John's wort (Hypericum perforatum), may reduce the systemic exposure of dabigatran. ${ }^{97}$

Dabigatran etexilate is currently marketed in several regions for VTE prophylaxis after total hip replacement or total knee arthroplasty on the basis of four major clinical trials (RE-NOVATE I and II, RE-MODEL, and RE-MOBILIZE).$^{98-101}$ It is also approved in several regions for stroke prevention in patients with atrial fibrillation based on the results of the RE-LY clinical trial. ${ }^{102}$ The main results of the studies in the treatment of VTE (Table 5), some of them including data in patients with cancer, are discussed below.

\section{Long-term treatment of VTE}

RE-COVER ${ }^{103}$ was a randomized, double-blind, noninferiority trial involving patients with acute VTE who were initially given parenteral anticoagulation therapy for a median of 9 days. The investigators compared oral dabigatran, administered at a dose of $150 \mathrm{mg}$ twice daily, with warfarin dose-adjusted to achieve an INR of 2.0-3.0. The study randomized 2564 patients, of whom 2539 were included in the analysis (dabigatran, 1274; warfarin, 1265). Of these, 121 (4.8\%) had active cancer at baseline. In total, $2.4 \%$ of patients $(30 / 1274)$ on dabigatran and $2.1 \%(27 / 1265)$ on warfarin had recurrent symptomatic, objectively confirmed VTE and related deaths at 6 months (main study outcome, HR 1.10; 95\% CI 0.65-1.84). Nonfatal pulmonary embolism occurred in 13 patients assigned to dabigatran and in seven patients assigned to warfarin (HR 1.85 ; 95\% CI 0.74-4.64). Major bleeding rates were similar in the dabigatran and warfarin groups (1.6\% versus $1.9 \%$; HR 0.82 ; 95\% CI $0.45-1.48)$, but episodes of any clinically relevant bleeding occurred less frequently with dabigatran than with warfarin $(5.6 \%$ versus $8.8 \%$; HR 0.63 ; $95 \%$ CI $0.47-0.84)$. The relative risk of recurrent VTE with dabigatran versus warfarin was similar among the 121 patients with cancer (RR 0.59; 95\% CI 0.10-3.43) (Table 6). The relative risk of bleeding with dabigatran as compared with warfarin was similar among predefined subgroups, ${ }^{103}$ but the specific results in cancer patients have not been published.

The twin study, RECOVER II, ${ }^{104}$ included 2568 patients with acute VTE, and yielded very similar results to those of RECOVER (Table 5). No subgroup analysis is currently available. The authors concluded that dabigatran is noninferior to warfarin in the treatment of acute VTE and has a lower risk for bleeding.

\section{Extended treatment of VTE}

The RE-MEDY study ${ }^{105}$ compared extended treatment of VTE with dabigatran versus warfarin for a mean of 16 months in patients who had initially received 3-12 months of anticoagulant therapy. The study included 2856 patients, of whom 119 (4.2\%) had active cancer. Dabigatran showed noninferior efficacy compared with warfarin with respect to recurrent VTE events (1.8\% versus 1.3\%; HR 1.44; 95\% CI $0.78-2.64 ; P=0.03$ for the prespecified noninferiority margin). There were fewer clinically relevant bleeding episodes but more acute coronary syndromes with dabigatran than with warfarin (Table 5). Death rates were similar in both groups. In cancer patients, recurrent VTE rates were 3.3\% (two of 60) in the dabigatran group and $1.7 \%$ (one of 59 ) in the warfarin group. 
RE-SONATE ${ }^{105}$ investigated the extended treatment of VTE with dabigatran compared with placebo for 6 additional months in patients who had completed 6-18 months of anticoagulant therapy. Active cancer was an exclusion criterion. Dabigatran was superior to placebo in reducing the risk of recurrent VTE (0.4\% versus 5.6\%; HR 0.08; 95\% CI $0.02-0.25)$, but was associated with an increase in clinically relevant bleeding (5.3\% versus $1.8 \%$; HR 2.92; 95\% CI 1.52 5.60 , Table 5). Rates of cardiovascular events and deaths were similar in both groups. The benefit in reduction of recurrent VTE was maintained at one-year post-treatment follow-up (7.8\% versus $11.6 \%$; absolute risk difference $-3.8 \%$; $95 \%$ CI $-7.1 \%$ to $-0.5 \% ; P=0.0261) .{ }^{106}$

\section{Discussion}

Currently, the two major areas of investigation in VTE prophylaxis and treatment of cancer patients are characterization of ambulatory medical patients on chemotherapy (type and stage of cancer and type of chemotherapy) who would benefit most from prophylactic anticoagulation in terms of survival, thrombotic and bleeding events, and quality of life on the one hand, and establishment of the optimal duration of anticoagulation in patients with VTE and cancer.

With respect to the new parenteral indirect FXa inhibitors, specific data in cancer patients are only available for semuloparin (Table 6). Data from the SAVE-ONCO study ${ }^{35-37}$ in cancer patients on chemotherapy are promising, but have been insufficient to gain regulatory approval. Key unanswered questions relate to the effect of anticoagulant treatment on quality of life and whether such treatment affects tumor growth or dissemination. Most important, additional evidence is required as to which patients with cancer (ie, the type and stage of cancer) would benefit most, what is the magnitude of the survival benefit, and if there is a benefit in cancers that respond poorly to other therapies. ${ }^{107}$

Once-weekly idrabiotaparinux dosing may potentially improve patient adherence in comparison with daily doses of a vitamin $\mathrm{K}$ antagonist. ${ }^{108}$ Subgroup analyses in patients with deep vein thrombosis suggest a similar effect of the related compound, idraparinux, in patients with or without cancer. ${ }^{45}$ However, its long half-life may be a drawback in cancer patients, who frequently undergo invasive diagnostic or therapeutic interventions that may require rapid reversal and rapid reintroduction of anticoagulation. The availability of an antidote (avidin) for idrabiotaparinux may help to alleviate worries about its long half-life. ${ }^{48}$

The data available with the new oral agents from specific studies in cancer patients are limited to a small dose-finding trial with apixaban for thromboprophylaxis in patients undergoing chemotherapy, and using placebo as the comparator (ADVOCATE study, Table 6). ${ }^{74}$ Other thromboprophylaxis studies with new oral anticoagulants in medical patients, not focused on cancer patients, show a similar efficacy or the new anticoagulant in comparison with LMWH during active treatment and increased bleeding risk. ${ }^{63,74}$ In subgroup analyses of the MAGELLAN study, rivaroxaban showed a nonsignificant trend towards less efficacy compared with enoxaparin in patients with active cancer (Table 6). ${ }^{65}$ The new oral anticoagulants may offer advantages over vitamin $\mathrm{K}$ antagonists in long-term and extended treatment of VTE, such as once-daily dosing and no need for routine monitoring of its anticoagulant activity. A small pooled analysis of the cancer patients included in the EINSTEIN-DVT ${ }^{61}$ and EINSTEIN-PE ${ }^{62}$ studies suggests a similar efficacy and safety profile for rivaroxaban and warfarin in the long-term treatment of cancer patients with VTE (Figure 2). On the other hand, the new oral anticoagulants may eliminate the need for daily injection of LMWH in the treatment of VTE in cancer patients, but further specific studies are needed to demonstrate that the new agents are as effective and safe as the standard of care in cancer patients (LMWH).

There are pharmacodynamic differences between the old and new compounds, which may result in differential effects in cancer patients. The antithrombotic effect of LMWH is well established, and some of their pleiotropic effects, like inhibition of cell-cell interaction by blocking cell adhesion molecules (selectins), inhibition of extracellular matrix protease heparanase, and inhibition of angiogenesis, ${ }^{109}$ might translate into a survival benefit in patients with cancer. ${ }^{107}$ All these pleiotropic effects are unlikely to be shown with the synthetic and more selective new anticoagulants. ${ }^{110,111}$

The optimal duration of treatment with an anticoagulant after a first episode of VTE has not been studied in patients with cancer. According to current guidelines, patients with permanent risk factors for VTE, such as those with active cancer or receiving chemotherapy, may benefit from extended duration of anticoagulant therapy beyond 3-6 months (Table 1). ${ }^{15}$ Some studies with the new anticoagulants have assessed the issue of extending VTE treatment beyond 3-6 months in comparison with warfarin ${ }^{105}$ or placebo,,${ }^{61,76,105}$ but the percentage of patients with cancer included in these studies is very limited and further specific studies are needed.

With respect to safety, the lack of specific antidotes for the new oral anticoagulants may be problematic in patients with cancer, given that these patients are more likely to develop major bleeding complications during anticoagulant 


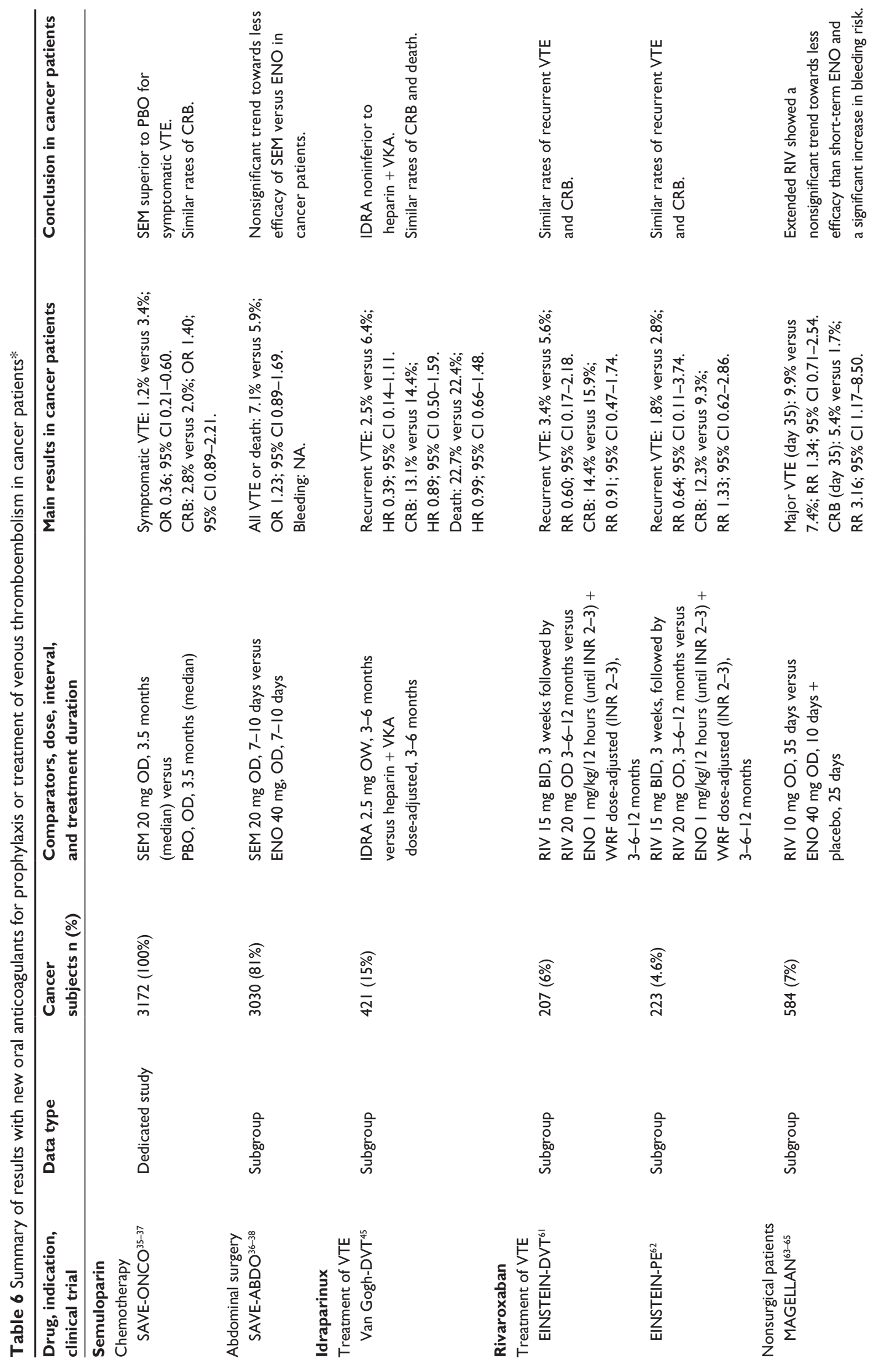




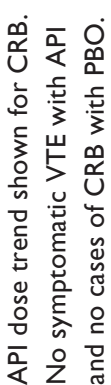

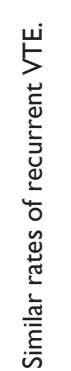

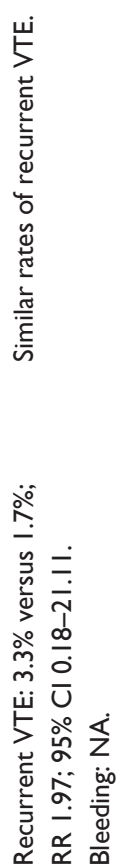
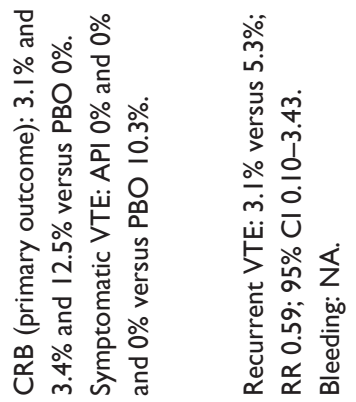

ฉి

ำ

烏

号 treatment than those without malignancy. ${ }^{12}$ On the positive side, new oral anticoagulants may be potentially useful for anticoagulation in the management of patients with heparininduced thrombocytopenia, a rare but serious complication of heparin treatment, ${ }^{112}$ because they do not interact with PF4 in vitro, ${ }^{113,114}$ but further clinical studies are needed before recommendations can be made in this setting.

\section{Conclusion}

There are limited data available on the use of newer anticoagulants in cancer patients. Whether novel anticoagulants have a role in cancer patients is currently unknown. Further specific data in cancer patients are needed before these agents could be recommended for prophylaxis or treatment of VTE in this special population.

\section{Disclosure}

The contents of this review are solely the responsibility of the authors and do not necessarily represent the official view of their institutions or any other party. The authors declare no conflicts of interest in this work.

\section{References}

1. Mackman N. Triggers, targets and treatments for thrombosis. Nature. 2008;451:914-918.

2. Niederlaender E. Causes of death in the EU. Statistics in focus. Population and social conditions. Eurostat. 2006;10:1-12.

3. Bouillaud JB. De l'Obliteration des veines et de son influence sur la formation des hydropisies partielles: consideration sur la hydropisies passive et general (Obliteration of the veins and its influence on the formation of partial dropsies: consideration of the general and passive dropsies). Arch Gen Med. 1823;1:188-204. French.

4. Trousseau A. Phlegmasia alba dolens. In: Baillière JB, editor. Clinique Medicale de l'Hotel-Dieu de Paris Volume 3, 2nd ed. Paris, France: JB Baillière and Sons; 1865.

5. Heit JA, Silverstein MD, Mohr DN, Petterson TM, O'Fallon WM, Melton LJ III. Risk factors for deep vein thrombosis and pulmonary embolism: a population-based case-control study. Arch Intern Med. 2000;160:809-815.

6. Chew HK, Wun T, Harvey D, Zhou H, White RH. Incidence of venous thromboembolism and its effect on survival among patients with common cancers. Arch Intern Med. 2006;166:458-464.

7. Sørensen HT, Sværke C, Farkas DK, et al. Superficial and deep venous thrombosis, pulmonary embolism and subsequent risk of cancer. Eur J Cancer. 2012;48:586-593.

8. Prandoni P, Falanga A, Piccioli A. Cancer and venous thromboembolism. Lancet Oncol. 2005;6:401-410.

9. Falanga A, Donati MB. Pathogenesis of thrombosis in patients with malignancy. Int J Hematol. 2001;73:137-144.

10. Falanga A, Rickles FR. Management of thrombohemorrhagic syndromes (THS) in hematologic malignancies. Hematology Am Soc Hematol Educ Program. 2007:165-171.

11. Nalluri SR, Chu D, Keresztes R, Zhu X, Wu S. Risk of venous thromboembolism with the angiogenesis inhibitor bevacizumab in cancer patients: a meta-analysis. JAMA. 2008;300:2277-2285.

12. Prandoni P, Lensing AW, Piccioli A, et al. Recurrent venous thromboembolism and bleeding complications during anticoagulant treatment in patients with cancer and venous thrombosis. Blood. 2002;100:3484-3488. 
13. Gould MK, Garcia DA, Wren SM, et al. Prevention of VTE in nonorthopedic surgical patients: antithrombotic therapy and prevention of thrombosis, 9th ed. American College of Chest Physicians Evidence-Based Clinical Practice Guidelines. Chest. 2012; 141(Suppl 2):e227S-e277S.

14. Kahn SR, Lim W, Dunn AS, et al. Prevention of VTE in nonsurgical patients: antithrombotic therapy and prevention of thrombosis. 9th ed. American College of Chest Physicians Evidence-Based Clinical Practice Guidelines. Chest. 2012;141(Suppl 2):e195S-e226S.

15. Kearon C, Akl EA, Comerota AJ, et al. Antithrombotic therapy for VTE disease: antithrombotic therapy and prevention of thrombosis. 9th ed. American College of Chest Physicians Evidence-Based Clinical Practice Guidelines. Chest. 2012;141(Suppl 2):e419S-e494S.

16. Farge D, Debourdeau P, Beckers M, et al. International clinical practice guidelines for the treatment and prophylaxis of venous thromboembolism in patients with cancer. $J$ Thromb Haemost. 2013;11:56-70.

17. Mandala M, Falanga A, Roila F. Management of venous thromboembolism [VTE] in cancer patients: ESMO Clinical Practice Guidelines. Ann Oncol. 2011;22 Suppl 6:vi85-vi92.

18. Lyman GH, Khorana AA, Falanga A, et al. American Society of Clinical Oncology guideline: recommendations for venous thromboembolism prophylaxis and treatment in patients with cancer. J Clin Oncol. 2007;25:5490-5505.

19. National Comprehensive Cancer Network Clinical Practice Guidelines in Oncology Venous Thromboembolic Disease version 2.2011. Available from: http://www.nccn.org/professionals/physician_gls/f_ guidelines.asp\#supportive. Accessed October 23, 2012.

20. Mann KG, Brummel $\mathrm{K}$, Butenas $\mathrm{S}$. What is all that thrombin for? J Thromb Haemost. 2003;1:1504-1514.

21. Davie EW, Kulman JD. An overview of the structure and function of thrombin. Semin Thromb Hemost. 2006;32 Suppl 1:3-15.

22. Siller-Matula JM, Schwameis M, Blann A, Mannhalter C, Jilma B. Thrombin as a multi-functional enzyme. Focus on in vitro and in vivo effects. Thromb Haemost. 2011;106:1020-1033.

23. Hu L, Lee M, Campbell W, Perez-Soler R, Karpatkin S. Role of endogenous thrombin in tumor implantation, seeding, and spontaneous metastasis. Blood. 2004;104:2746-2751.

24. DeFeo K, Hayes C, Chernick M, Ryn JV, Gilmour SK. Use of dabigatran etexilate to reduce breast cancer progression. Cancer Biol Ther. 2010;10:1001-1008.

25. Gómez-Outes A, Suárez-Gea ML, Calvo-Rojas G, et al. Discovery of anticoagulant drugs: a historical perspective. Curr Drug Discov Technol. 2012;9:83-104.

26. Apostolakis S, Lip GY. Novel oral anticoagulants: focus on the direct factor Xa inhibitor darexaban. Expert Opin Investig Drugs. 2012;21:1057-1064.

27. Ahrens I, Peter K, Lip GY, Bode C. Development and clinical applications of novel oral anticoagulants. Part II. Drugs under clinical investigation. Discov Med. 2012;13:445-450.

28. Viskov C, Just M, Laux V, Mourier P, Lorenz M. Description of the chemical and pharmacological characteristics of a new hemisynthetic ultra-low-molecular-weight heparin, AVE5026. J Thromb Haemost. 2009;7:1143-1151.

29. Dubruc C, Karimi-Anderesi N, Lunven C, Zhang M, Grossmann M, Potgieter H. Pharmacokinetics of a new, ultra-low molecular weight heparin, semuloparin (AVE5026), in healthy subjects. Results from the first phase I studies. Blood. 2009;114:Abstract 1073.

30. Gómez-Outes A, Suárez-Gea ML, Lecumberri R, Rocha E, Pozo-Hernández C, Vargas-Castrillón E. New parenteral anticoagulants in development. Ther Adv Cardiovasc Dis. 2011;5:33-59.

31. Eikelboom JW, Weitz JI. New anticoagulants. Circulation. 2010;121: $1523-1532$.

32. Lassen MR, Fisher W, Mouret P, Agnelli G, et al; SAVE Investigators. Semuloparin for prevention of venous thromboembolism after major orthopedic surgery: results from three randomized clinical trials, SAVE-HIP1, SAVE-HIP2 and SAVE-KNEE. J Thromb Haemost. $2012 ; 10: 822-832$.
33. Fisher W, Agnelli G, George D, et al. Extended venous thromboembolism (VTE) prophylaxis after hip fracture surgery with the ultralow-molecular-weight heparin (ULMWH) semuloparin. Pathophysiol Haemos Thromb. 2009/2010;37 Suppl 1:OC681.

34. Turpie AGG, Agnelli G, Fisher W, et al. Benefit to-risk profile of the ultra-low-molecular weight heparin (ULMWH) semuloparin for prevention of venous thromboembolism (VTE): a meta-analysis of 3 major orthopaedic surgery studies. Pathophysiol Haemos Thromb. 2009/2010;37 Suppl 1:OC332.

35. Agnelli G, George DJ, Kakkar AK, et al; SAVE-ONCO Investigators. Semuloparin for thromboprophylaxis in patients receiving chemotherapy for cancer. $N$ Engl J Med. 2012;366:601-609.

36. Sanofi Research and Development. NDA 203213. Semuloparin Sodium. Oncologic Drugs Advisory Committee Meeting, June 20, 2012. Available from: http://www.fda.gov/downloads/AdvisoryCommittees/ CommitteesMeetingMaterials/Drugs/OncologicDrugsAdvisoryCom mittee/UCM308562.pdf. Accessed December 29, 2012.

37. Food and Drug Administration Briefing Document. NDA 203213. Semuloparin sodium. Oncologic Drugs Advisory Committee Meeting, June 20, 2012. Available from: http://www.fda.gov/downloads/ advisorycommittees/committeesmeetingmaterials/drugs/oncolog icdrugsadvisorycommittee/ucm308561.pdf. Accessed December 29, 2012.

38. Kakkar A, Agnelli G, Fisher W, et al. The ultra-low-molecularweight heparin semuloparin for prevention of venous thromboembolism in patients undergoing major abdominal surgery. Abstract 188 presented at the 52nd ASH Annual Meeting and Exposition. Orlando, FL, December 4-7, 2010. Available from: https://ash.confex. com/ash/2010/webprogram/Paper31003.html. Accessed December 29, 2012.

39. Herbert JM, Hérault JP, Bernat A, et al. Biochemical and pharmacological properties of SANORG 34006, a potent and long-acting synthetic pentasaccharide. Blood. 1998;91:4197-4205.

40. Savi P, Herault JP, Duchaussoy P, et al. Reversible biotinylated oligosaccharides. A new approach for a better management of anticoagulant therapy. J Thromb Haemost. 2008;6:1697-1706.

41. Ma Q, Fareed J. Idraparinux sodium. Sanofi-Aventis. I Drugs. 2004;7: 1028-1034.

42. Veyrat-Follet C, Vivier N, Trellu M, Dubruc C, Sanderink GJ. The pharmacokinetics of idraparinux, a long-acting indirect factor $\mathrm{Xa}$ inhibitor: population pharmacokinetic analysis from phase III clinical trials. J Thromb Haemost. 2009;7:559-565.

43. Harenberg J, Jörg I, Vukojevic Y, Mikus G, Weiss C. Anticoagulant effects of idraparinux after termination of therapy for prevention of recurrent venous thromboembolism: observations from the van Gogh trials. Eur J Clin Pharmacol. 2008;64:555-563.

44. Buller HR, Cohen AT, Davidson B, et al; van Gogh Investigators. Idraparinux versus standard therapy for venous thromboembolic disease. N Engl J Med. 2007;357:1094-1104.

45. van Doormaal FF, Cohen AT, Davidson BL, et al. Idraparinux versus standard therapy in the treatment of deep venous thrombosis in cancer patients: a subgroup analysis of the Van Gogh DVT trial. Thromb Haemost. 2010;104:86-91.

46. Buller HR, Cohen AT, Davidson B, et al; van Gogh Investigators. Extended prophylaxis of venous thromboembolism with idraparinux. N Engl J Med. 2007;357:1105-1112.

47. Harenberg J, Vukojevic Y, Mikus G, Joerg I, Weiss C. Long elimination half-life of idraparinux may explain major bleeding and recurrent events of patients from the van Gogh trials. J Thromb Haemost. 2008;6:890-892.

48. Paty I, Trellu M, Destors JM, Cortez P, Boëlle E, Sanderink G. Reversibility of the anti-FXa activity of idrabiotaparinux (biotinylated idraparinux) by intravenous avidin infusion. J Thromb Haemost. 2010;8:722-729.

49. Equinox Investigators. Efficacy and safety of once weekly subcutaneous idrabiotaparinux in the treatment of patients with symptomatic deep venous thrombosis. J Thromb Haemost. 2011;9:92-99. 
50. Büller HR, Gallus AS, Pillion G, Prins MH, Raskob GE; Cassiopea Investigators. Enoxaparin followed by once-weekly idrabiotaparinux versus enoxaparin plus warfarin for patients with acute symptomatic pulmonary embolism: a randomised, double-blind, double-dummy, non-inferiority trial. Lancet. 2012;379:123-129.

51. Kubitza D, Becka M, Voith B, Zuehlsdorf M, Wensing G. Safety, pharmacodynamics, and pharmacokinetics of single doses of BAY 59-7939, an oral, direct factor Xa inhibitor. Clin Pharmacol Ther. 2005;78:412-421.

52. Kubitza D, Becka M, Wensing G, Voith B, Zuehlsdorf M. Safety, pharmacodynamics, and pharmacokinetics of BAY 59-7939 - an oral, direct Factor Xa inhibitor - after multiple dosing in healthy male subjects. Eur J Clin Pharmacol. 2005;61:873-880.

53. Kubitza D, Becka M, Roth A, Mueck W. Dose-escalation study of the pharmacokinetics and pharmacodynamics of rivaroxaban in healthy elderly subjects. Curr Med Res Opin. 2008;24:2757-2765.

54. Lang D, Freudenberger C, Weinz C. In vitro metabolism of rivaroxaban, an oral, direct factor Xa inhibitor, in liver microsomes and hepatocytes of rats, dogs, and humans. Drug Metab Dispos. 2009;37: 1046-1055.

55. Xarelto ${ }^{\circledR}$ (rivaroxaban). Summary of product characteristics. Available from: http://www.ema.europa.eu/docs/en_GB/document_library/ EPAR_-_Product_Information/human/000944/WC500057108.pdf Accessed January 4, 2013.

56. Eriksson BI, Borris LC, Friedman RJ, et al. Rivaroxaban versus enoxaparin for thromboprophylaxis after hip arthroplasty. $N$ Engl $J$ Med. 2008;358:2765-2775.

57. Kakkar AK, Brenner B, Dahl OE, et al. Extended duration rivaroxaban versus short-term enoxaparin for the prevention of venous thromboembolism after total hip arthroplasty: a double-blind, randomised controlled trial. Lancet. 2008;372:31-39.

58. Lassen MR, Ageno W, Borris LC, et al. Rivaroxaban versus enoxaparin for thromboprophylaxis after total knee arthroplasty. $N$ Engl J Med. 2008;358:2776-2786.

59. Turpie AG, Lassen MR, Davidson BL, et al. Rivaroxaban versus enoxaparin for thromboprophylaxis after total knee arthroplasty (RECORD4): a randomised trial. Lancet. 2009;373:1673-1680.

60. Patel MR, Mahaffey KW, Garg J, et al. Rivaroxaban versus warfarin in nonvalvular atrial fibrillation. $N$ Engl J Med. 2011;365: 883-891.

61. Bauersachs R, Berkowitz SD, Brenner B, et al; EINSTEIN Investigators. Oral rivaroxaban for symptomatic venous thromboembolism. N Engl J Med. 2010;363:2499-2510.

62. Büller HR, Prins MH, Lensin AW, et al; EINSTEIN-PE Investigators Oral rivaroxaban for the treatment of symptomatic pulmonary embolism. N Engl J Med. 2012;366:1287-1297.

63. Cohen AT, Spiro TE, Büller HR, et al. Extended-duration rivaroxaban thromboprophylaxis in acutely ill medical patients: MAGELLAN study protocol. J Thromb Thrombolysis. 2011;31:407-416.

64. Cohen AT, Spiro TE, Büller HR, et al. Rivaroxaban for thromboprophylaxis in acutely ill medical patients. $N$ Engl J Med. 2013;368: 513-523.

65. Cohen AT, Spiro TE, Buller HR, et al. Rivaroxaban versus enoxaparin for the prevention of venous thromboembolism in acutely ill medical patients: Magellan subgroup analyses. J Thromb Hemost. 2011;9 Suppl 2:Abstract O-MO-034.

66. Wong PC, Crain EJ, Xin B, et al. Apixaban, an oral, direct and highly selective factor Xa inhibitor: in vitro, antithrombotic and antihemostatic studies. J Thromb Haemost. 2008;6:820-829.

67. Eliquis ${ }^{\circledR}$ (apixaban). Summary of product characteristics. Available from: http://www.ema.europa.eu/docs/en_GB/document_library/ EPAR_-_Product_Information/human/002148/WC500107728.pdf. Accessed January 8, 2013.

68. Wang L, Zhang D, Raghavan N, et al. In vitro assessment of metabolic drug-drug interaction potential of apixaban through cytochrome P450 phenotyping, inhibition, and induction studies. Drug Metab Dispos. 2010;38:448-458.
69. Raghavan N, Frost CE, Yu Z, et al. Apixaban metabolism and pharmacokinetics after oral administration to humans. Drug Metab Dispos. 2009;37:74-81.

70. Lassen MR, Raskob GE, Gallus A, Pineo G, Chen D, Portman RJ. Apixaban or enoxaparin for thromboprophylaxis after knee replacement. N Engl J Med. 2009;361:594-604.

71. Lassen MR, Raskob GE, Gallus A, et al. Apixaban versus enoxaparin for thromboprophylaxis after knee replacement (ADVANCE-2): a randomised double-blind trial. Lancet. 2010;375:807-815.

72. Lassen MR, Gallus A, Raskob GE, et al. Apixaban versus enoxaparin for thromboprophylaxis after hip replacement. $N$ Engl J Med. 2010; 363:2487-2498

73. Granger $\mathrm{CB}$, Alexander JH, McMurray JJ, et al. Apixaban versus warfarin in patients with atrial fibrillation. $N$ Engl J Med. 2011;365: 981-992.

74. Levine $\mathrm{MN}, \mathrm{Gu} \mathrm{C}$, Liebman HA, et al. A randomized phase II trial of apixaban for the prevention of thromboembolism in patients with metastatic cancer. J Thromb Haemost. 2012;10:807-814.

75. Goldhaber SZ, Leizorovicz A, Kakkar AK, et al. Apixaban versus enoxaparin for thromboprophylaxis in medically ill patients. $N$ Engl $J$ Med. 2011;365:2167-2177.

76. Agnelli G, Buller HR, Cohen A, et al. Apixaban for extended treatment of venous thromboembolism. N Engl J Med. 2013;368:699-708.

77. Furugohri T, Isobe K, Honda Y, et al. DU-176b, a potent and orally active factor Xa inhibitor: in vitro and in vivo pharmacological profiles. J Thromb Haemost. 2008;6:1542-1549.

78. Morishima Y, Honda Y, Kamisato C, et al. Comparison of antithrombotic and haemorrhagic effects of edoxaban, an oral direct factor Xa inhibitor, with warfarin and enoxaparin in rats. Thromb Res. 2012;130: 514-519.

79. Ogata K, Mendell-Harary J, Tachibana M, et al. Clinical safety, tolerability, pharmacokinetics, and pharmacodynamics of the novel factor Xa inhibitor edoxaban in healthy volunteers. J Clin Pharmacol. 2010; 50:743-753

80. Kawaji H, Ishii M, Tamaki Y, Sasaki K, Takagi M. Edoxaban for prevention of venous thromboembolism after major orthopedic surgery. Orthop Res Rev. 2012;4:53-64.

81. Bathala MS, Masumoto H, Oguma T, He L, Lowrie C, Mendell J. Pharmacokinetics, biotransformation, and mass balance of edoxaban, a selective, direct factor Xa inhibitor, in humans. Drug Metab Dispos. 2012;40:2250-2255.

82. Fuji T, Fujita S, Tachibana S, et al. Efficacy and safety of edoxaban versus enoxaparin for the prevention of venous thromboembolism following total hip arthroplasty: STARS J-V trial. Blood. 2010;116: Abstract 3320.

83. Fuji T, Wang CJ, Fujita S, et al. Edoxaban versus enoxaparin for thromboprophylaxis after total knee arthroplasty: the STARS E-3 Trial. Pathophysiol Haemost Thromb. 2010;37 Suppl 1: Abstract A20.

84. Fujita S, Fuji T, Tachibana S, Nakamura, Kawai Y. Safety and efficacy of edoxaban in patients undergoing hip fracture surgery. Pathophysiol Haemost Thromb. 2010;37 Suppl 1:Abstract A95.

85. Fuji T, Fujita S, Tachibana S, Kawai Y. Edoxaban versus enoxaparin for the prevention of venous thromboembolism: pooled analysis of venous thromboembolism and bleeding from STARS E-III and STARS J-V. Blood. 2011;118:Abstract 208.

86. Weitz JI, Connolly SJ, Patel I, et al. Randomised, parallel-group, multicentre, multinational phase 2 study comparing edoxaban, an oral factor Xa inhibitor, with warfarin for stroke prevention in patients with atrial fibrillation. Thromb Haemost. 2010;104: 633-641.

87. Ruff CT, Giugliano RP, Antman EM, et al. Evaluation of the novel factor Xa inhibitor edoxaban compared with warfarin in patients with atrial fibrillation: design and rationale for the Effective aNticoaGulation with factor xA next GEneration in Atrial Fibrillation-Thrombolysis In Myocardial Infarction study 48 (ENGAGE AF-TIMI 48). Am Heart $J$. 2010;160:635-641. 
88. Zhang P, Huang W, Wang L, et al. Discovery of betrixaban (PRT054021), N-(5-chloropyridin-2-yl)-2-(4-(N,N-dimethylcarbamimidoyl)benzamido)-5-methoxybenz amide, a highly potent, selective, and orally efficacious factor Xa inhibitor. Bioorg Med Chem Lett. 2009; 19:2179-2185.

89. Abe K, Siu G, Edwards S, et al. Animal models of thrombosis help predict the human therapeutic concentration of PRT54021, a potent oral factor Xa inhibitor. Blood. 2006;108:Abstract 901.

90. Hutchaleelaha A, Ye C, Song Y, Lorenz T, Gretler D, Lambing JL. Metabolism and disposition of betrixaban and its lack of interaction with major CYP enzymes. Blood. 2012;120:Abstract 2266.

91. Turpie AG, Bauer KA, Davidson BL, et al. A randomized evaluation of betrixaban, an oral factor Xa inhibitor, for prevention of thromboembolic events after total knee replacement (EXPERT). Thromb Haemost. 2009;101:68-76.

92. Ezekowitz MD. A phase 2, randomized, parallel group, dose-finding, multicenter, multinational study of the safety, tolerability and pilot efficacy of three blinded doses of the oral factor Xa inhibitor betrixaban compared with open-label dose-adjusted warfarin in patients with non-valvular atrial fibrillation (EXPLORE-Xa). Presented at the American College of Cardiology 59th Annual Scientific Sessions, Atlanta, GA, March 14-16, 2010. Available from: http://assets.cardiosource.com/ezekowitz_explore1.ppt\#636,1,EXPLORE-Xa. Accessed January 7, 2013.

93. Mungall D. BIBR-1048 Boehringer Ingelheim. Curr Opin Investig Drugs. 2002;3:905-907.

94. Stangier J. Clinical pharmacokinetics and pharmacodynamics of the oral direct thrombin inhibitor dabigatran etexilate. Clin Pharmacokinet. 2008;47:285-295.

95. Trocóniz IF, Tillmann C, Liesenfeld KH, Schäfer HG, Stangier J. Population pharmacokinetic analysis of the new oral thrombin inhibitor dabigatran etexilate (BIBR 1048) in patients undergoing primary elective total hip replacement surgery. J Clin Pharmacol. 2007;47: 371-382.

96. Blech S, Ebner T, Ludwig-Schwellinger E, Stangier J, Roth W. The metabolism and disposition of the oral direct thrombin inhibitor, dabigatran, in humans. Drug Metab Dispos. 2008;36:386-399.

97. Pradaxa ${ }^{\circledR}$ (dabigatran). Summary of product characteristics. Available from: http://www.ema.europa.eu/docs/en_GB/document_library/ EPAR_-_Product_Information/human/000829/WC500041059.pdf. Accessed January 8, 2013.

98. Eriksson BI, Dahl OE, Rosencher N, et al. Dabigatran etexilate versus enoxaparin for prevention of venous thromboembolism after total hip replacement: a randomised, double-blind, non-inferiority trial. Lancet. 2007;370:949-956.

99. Eriksson BI, Dahl OE, Huo MH, Kurth AA, Hantel S, Hermansson K, et al. Oral dabigatran versus enoxaparin for thromboprophylaxis after primary total hip arthroplasty (RE-NOVATE II*). A randomised, double-blind, non-inferiority trial. Thromb Haemost. 2011;105: 721-729.

100. Eriksson BI, Dahl OE, Rosencher N, et al. Oral dabigatran etexilate versus subcutaneous enoxaparin for the prevention of venous thromboembolism after total knee replacement: the RE-MODEL randomized trial. J Thromb Haemost. 2007;5:2178-2185.

Vascular Health and Risk Management

\section{Publish your work in this journal}

Vascular Health and Risk Management is an international, peerreviewed journal of therapeutics and risk management, focusing on concise rapid reporting of clinical studies on the processes involved in the maintenance of vascular health; the monitoring, prevention and treatment of vascular disease and its sequelae; and the involvement of
101. Ginsberg JS, Davidson BL, Comp PC, et al; RE-MOBILIZE Writing Committee. Oral thrombin inhibitor dabigatran etexilate vs North American enoxaparin regimen for prevention of venous thromboembolism after knee arthroplasty surgery. J Arthroplasty. 2009;24:1-9.

102. Connolly SJ, Ezekowitz MD, Yusuf S, et al. Dabigatran versus warfarin in patients with atrial fibrillation. N Engl J Med. 2009;361: 1139-1151.

103. Schulman S, Kearon C, Kakkar AK, et al. Dabigatran versus warfarin in the treatment of acute venous thromboembolism. $N$ Engl J Med. 2009;361:2342-2352.

104. Schulman S, Kakkar AK, Schellong SM, et al. A randomized trial of dabigatran versus warfarin in the treatment of acute venous thromboembolism (RE-COVER II). Blood. 2011;118:Abstract 205.

105. Schulman S, Kearon C, Kakkar AK, et al. Extended use of dabigatran, warfarin, or placebo in venous thromboembolism. $N$ Engl J Med. 2013;368:709-718.

106. Schulman S, Baanstra D, Eriksson H, et al. Benefit of extended maintenance therapy for venous thromboembolism with dabigatran etexilate is maintained over 1 year of post-treatment follow-up. Blood. 2012;120:Abstract 21.

107. Akl EA, Schünemann HJ. Routine heparin for patients with cancer? One answer, more questions. N Engl J Med. 2012;366:661-662.

108. Prins MH, Leguet P, Gilet H, Roborel de Climens A. Convenience of the new long-acting anticoagulant idraparinux (IDRA) versus vitamin $\mathrm{K}$ antagonist (vitamin $\mathrm{K}$ antagonist) in patients with deep venous thrombosis (DVT). J Thromb Haemost. 2007;5 Suppl 2: Abstract P-T-552.

109. Borsig L. Heparin as an inhibitor of cancer progression. Prog Mol Biol Transl Sci. 2010;93:335-349.

110. Stevenson JL, Choi SH, Varki A. Differential metastasis inhibition by clinically relevant levels of heparins-correlation with selectin inhibition, not antithrombotic activity. Clin Cancer Res. 2005; 11(19 Pt 1):7003-7011.

111. Khorana AA, Sahni A, Altland OD, Francis CW. Heparin inhibition of endothelial cell proliferation and organization is dependent on molecular weight. Arterioscler Thromb Vasc Biol. 2003;23:2110-2115.

112. Linkins LA, Dans AL, Moores LK, et al. Treatment and prevention of heparin-induced thrombocytopenia: Antithrombotic Therapy and Prevention of Thrombosis, 9th ed. American College of Chest Physicians Evidence-Based Clinical Practice Guidelines. Chest. 2012; 141(Suppl 2):e495S-e530S.

113. Krauel K, Hackbarth C, Fürll B, Greinacher A. Heparin-induced thrombocytopenia: in vitro studies on the interaction of dabigatran, rivaroxaban, and low-sulfated heparin, with platelet factor 4 and antiPF4/heparin antibodies. Blood. 2012;119:1248-1255.

114. Walenga JM, Prechel M, Jeske WP, et al. Rivaroxaban - an oral, direct Factor Xa inhibitor - has potential for the management of patients with heparin-induced thrombocytopenia. Br J Haematol. 2008;143:92-99.

metabolic disorders, particularly diabetes. This journal is indexed on PubMed Central and MedLine. The manuscript management system is completely online and includes a very quick and fair peer-review system, which is all easy to use. Visit http://www.dovepress.com/ testimonials.php to read real quotes from published authors. 